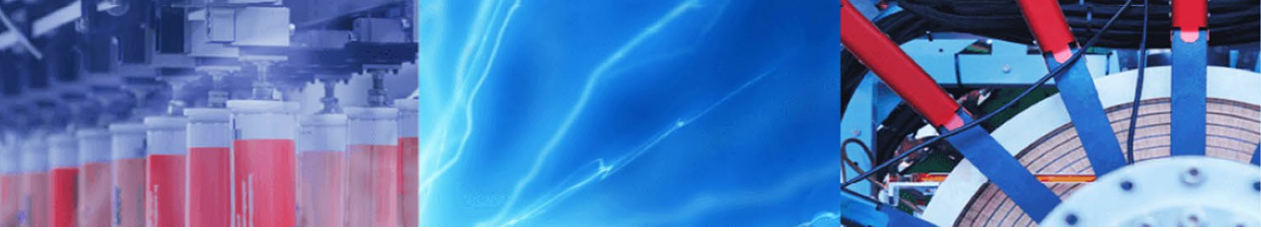

Research Article

\title{
Tribological behavior of aluminum silicon eutectic alloy based composites under dry and wet sliding for variable load and sliding distance
}

\author{
Pranav Dev Srivyas $^{1}$ (1) $\cdot$ M. S. Charoo ${ }^{1}$
}

Received: 1 April 2020 / Accepted: 26 August 2020 / Published online: 9 September 2020

(c) Springer Nature Switzerland AG 2020

\begin{abstract}
In most of the studies, the tribopair as well as tribo-components interfaces are lubricated using different lubricating oil or solid tribofilms. In the present study, the anti-friction and anti-wear performance of the tribopair is improved using nanoAluminium Oxide $\left(\mathrm{Al}_{2} \mathrm{O}_{3}\right)$ and Graphene Nano Platelets (GNP) as reinforcement for composite and additive for lubricant respectively. Composite material and nano lubricants have attracted the interest of many researchers around the globe to enhance the life, durability and to reduce the friction and wear losses of mechanical components. Hence the objective of this study is to provide an insight to friction and wear reduction behavior of $n-\mathrm{Al}_{2} \mathrm{O}_{3}$ and $\mathrm{GNP}$ from the tribological aspect. The samples are fabricated using Spark Plasma Sintering (SPS) rapid fabrication route and their tribological properties are determined against chromium-plated-chrome-steel under dry and wet conditions at room temperature using universal reciprocating tribometer. From the results, it is reported that composite samples with (PAO- $4+0.5 \mathrm{wt} \%$ $\mathrm{GNP}+\mathrm{OA}$ ) nano-lubricant exhibit excellent tribological properties. This reduction is friction and wear is attributed to the hard phase ceramic reinforcements and nano-additive in lubricant that provides excellent tribological performance as well as Oleic Acid (OA) which help to improve the dispersion stability of the nano particles in the lubricating oil. Different surface characterization tools i.e. Optical Microscopy, Scanning Electron Microscopy, Electron Dispersion Spectroscopy, 3D surface profilometer are used in this study to understand the wear and lubrication mechanism after tribological testing.
\end{abstract}

Keywords Friction $\cdot$ Wear $\cdot$ Abrasion $\cdot$ Plastic deformation $\cdot$ Delamination

\section{Introduction}

The prominent challenge for the materials engineers and scientist is to reduce the COF and wear rate of the tribocomponent interfaces for mechanical components. To overcome these challenges new innovations in the composite materials and lubrication technology are needed. Wear is a gradual removal of material due to the physical, mechanical or chemical phenomenon (Rubbing, Microcracks, Plastic Deformation, and corrosion) between the interacting solid interface surfaces [1]. Wear may be because of many mechanisms such as adhesion, abrasion, melt, delamination, fretting and corrosion but all these lead to a similar result that is material removal $[2,3]$. To reduce the wear effect, lubrication [4] is done on the contact surface by forming a smooth surface which reduces direct metal-metal contact and hence reduces wear. In general, there are certain ways to reduce the wear and to improve the tribological properties of the material which include: (a) modification in the morphology of the material. (b) By alloying interaction with hard materials followed by heat treatment which improves the wear resistance and also improve transition load capacity from mild to severe wear. (c) By surface modification that is by applying certain

Pranav Dev Srivyas, devpranav.srivyas_17@nitsri.net | ${ }^{1}$ Mechanical Engineering Department, National Institute of Technology, Srinagar, J\&K 19006, India. 
coatings on the material surface so that to reduce the friction and wear behavior of material. (d) By reinforcement modification that is embedding hard phase or lamellar solids to the Matrix material which overall improves the mechanical and tribological properties of the monolithic material or an alloy. Conventional alloys need improvement in terms of tribological and mechanical aspects for various high end applications. The improvement in mechanical and tribological properties can be further enhanced by incorporation of various reinforcements such as $\mathrm{SiC}, \mathrm{Al}_{2} \mathrm{O}_{3}$, Aluminum Nitride, Nickel aluminide, $\mathrm{B}_{4} \mathrm{C}$, $\mathrm{TiO}_{2}, \mathrm{MoS}_{2}, \mathrm{WS}_{2}$, CNT, Graphite, GNP, GO, Cenium dioxide, etc. [5-10]. Due to high hardness of reinforcement wear resistance increases and introduction of lamellar solid improves the load-carrying capacity and provides lubrication to the materials $[11,12]$.

Use of the lubricating oil is another means which can be used to reduce the friction and wear behavior and to improve the tribological properties of the materials. Inclusion of the lubricating oil film at the component interface help in reducing the adhesion behavior between the tribo interfaces, reduces the interface temperature generated due to frictional heat as well as reduce the excessive oxidation. Innovation in the field of lubricating oil is the introduction of the self-lubricating lamellar nano-additive that improves the lubricity and load bearing capacity of the lubricating oils. Lamellar materials $\left(\mathrm{MoS}_{2}, \mathrm{WS}_{2}\right.$, h-BN, Graphite, Graphene) are having weak Van der Waals force which cause the easy sliding at the interface thus reduce the frictional traction of the sliding surface. Dispersion stability of these nano additive in the lubricating oil is an issue. By adding the surfactant it can be resolved. The nanoparticle addition in the lubricating oil helps to fill the asperities gap by mending mechanism which in turns smooth the sliding surface interface and reduces the friction of the tribopair. Nano-additive particles in the lubricating oil also provides the rolling ball bearing action between the sliding interface that leads to change the sliding pure fiction motion mechanism to rolling friction motion mechanism which reduces the frictional behavior [13-15].

Many researchers contribute a lot to evaluate the tribological properties of advanced metal matrix composites of which few are summarized: Garbiec et al. [16] et al. studied the tribological behavior of Spark Plasma Sintered Fabricated Aluminum-Aluminum Oxide (5-20 vol\%) composites. It is reported that reinforcement enhances the tribological and mechanical properties of the composite sample. The maximum hardness of $1355 \mathrm{MPa}$ and compressive strength of $246 \mathrm{MPa}$ is achieved with $20 \mathrm{vol} \%$ of Aluminum Oxide reinforcement. Bhatt et al. [17] fabricated Al-Mg (0.5-5 wt\%) composites reinforced with $\mathrm{SiO}_{2}$ (5 wt\%) using ball Milling and Spark Plasma Sintering (SPS) fabrication route. Results reported that milling results in complete dispersion of $\mathrm{Mg}$ in the matrix material. The formation of alpine $\left(\mathrm{MgAl}_{2} \mathrm{O}_{3}\right)$ along with $\mathrm{Al}_{2} \mathrm{O}_{3}$ is reported. It is also observed that the hardness of the Nanocomposite is twice higher than the micro composite due to the proper distribution of the nanoparticles in the matrix. Saheb et al. [18] fabricate Al6061/CNT and Al2124/CNT composite using Spark Plasma Sintering. Results reported that composites with 1 weight $\%$ of reinforcement show better properties as compared to composite with 2 weight $\%$ of reinforcement, because of better dispersion; good adhesion and less agglomeration. The full dense sample is achieved at $500^{\circ} \mathrm{C}$ which shows better tribological properties. Al-Qutub et al. [19] studied the tribological behavior of Al6061/CNT (1 wt\%) composite fabricated by Spark Plasma Sintering. It is observed that under mild wear composite shows a lower wear coefficient and Coefficient of Friction (COF) compared to Al6061 alloy, but under severe wear condition composite have higher wear and COF compared to alloy. This is reported that the friction and wear behavior of CNT is influenced by applied load and there are threshold critical loads beyond that CNT have negative impact on the friction and wear of the material. Gurler et al. [20] studied the wear behavior of AIMgSi alloy reinforced with 3-5 wt $\%$ of $\mathrm{SiC}_{\mathrm{p}}$. Dry tribotest is conducted at speed of $2.64 \mathrm{~m} / \mathrm{s}$ for the sliding distance of $3200 \mathrm{~m}$. It is reported that $50-400 \%$ of reduction in wear is due to the addition of particle reinforcement in the alloy. Lim et al. [21] studied the wear of Al-Cu/Silicon Carbide (13 wt\%) composite under dry sliding conditions with a sliding speed of $1 \mathrm{~m} / \mathrm{s}$ for sliding distance $1000 \mathrm{~m}$ under varying load. From results, it is reported that wear coefficient increases as the load increases; with wear loss of $3 \mathrm{mg}$ at $30 \mathrm{~N}, 4 \mathrm{mg}$ at $50 \mathrm{~N}$ and $5 \mathrm{mg}$ at $70 \mathrm{~N}$. Alaneme et al. [22] studied the mechanical properties of Al6063 alloy reinforced with $\mathrm{SiC}$ and RHA. It is reported that tensile strength, specific strength and yield strength of composite increases with increase in the RHA reinforcement whereas fracture toughness decreases. It is observed that the reinforcement does not have any effect on the ductility and percentage elongation of the composite. Alaneme et al. [23] in another study investigate corrosion behavior of Al6063/BLA composite. From results it is reported that BLA improves corrosion resistance, which might be due to presence of $50 \%$ silica in $\mathrm{BLA}$ which has the potential of suppressing $\mathrm{Al}_{4} \mathrm{C}_{3}$ which causes corrosion in the composite. Wan et al. [24] in their study use nano-BN particle with different concentration (0.1 wt\%, $0.5 \mathrm{wt} \%$ and $1 \mathrm{wt} \%$ ) in the SAE15W40 lubricating oil. From this study it is reported that inclusion of nano particles in the lubricating oil improves the anti-friction and anti-wear properties of the lubricant significantly. Charoo et al. $[25,26]$ in their study report that the inclusion of IF-MoS 2 and h-BN nano additive in the SAE20W40 
lubricating oil improves the tribological performance of the lubricating oil. Kandanur et al. [27] in their study on the self-lubricating composite report that the graphene platelets as the composite reinforcement reduces the wear coefficient of the PTFE based composite. Liao et al. [28] reported that the graphene improves the tribological performance of the tribo-pair significantly. In this study on the metal-on-metal tribo-pair for hip replacement, it is observed that graphene layer reduces the friction and wear of $\mathrm{Co}-\mathrm{Cr}-\mathrm{Mo} / \mathrm{Co}-\mathrm{Cr}-\mathrm{Mo}$ artificial tribological joint. In addition to this graphene as reinforcement as well as nano-additive reduces the corrosion, oxidation of the lubricant and improves the lubricity of the base oil.

The purpose of the present study is to examine the tribological behaviour of Al-Si based advanced composite under dry as well as lubricating sliding conditions. In the current study, Eutectic Al-Si alloy is used as matrix materials in the composite's fabrication. The motivation behind the selection of nano- $\mathrm{Al}_{2} \mathrm{O}_{3}$; nano-GNP as reinforcement and nano-additive respectively is the eco-friendly, high thermal stability, better mechanical and tribological properties of these nano particles even at adverse conditions. These particles act as effective catalyst which helps in formation of adsorbed layer on the tribo-interface results in reduction of COF and wear. In this study, friction and wear studies are conducted on the composites sample under dry and lubricating conditions. Also study on the influence of GNP nano-additive on friction and wear reduction of the composite sample is conducted in this study. The lubricating tribological test are performed with different lubricant with and without nano additive particles. The tribo-test are conducted on composite/counter-body with varying load and sliding distance. The present study report, reduction in the Coefficient of Friction (COF) and wear volume which is mainly governed by the introduction of $n-\mathrm{Al}_{2} \mathrm{O}_{3}$ reinforcement in the base alloy matrix and GNP nano-additive which regulate exceptional lubrication mechanism during the tribo-testing. This encourages to use Al-Si based advanced composite for various high end tribological applications especially in the automotive (IC Engine) applications.

\section{Experimental method}

\subsection{Material Selection and Sample Fabrication}

Al-Si alloy powder (Aluminum-Balance; Silicon-10.24\%; Copper $<0.3 \%$; Magnesium $<0.1 \%$; Manganese $<0.15 \%$; Zinc $<0.2 \%$; Iron $<0.8 \%$;) purchased from Intelligent material Pvt. Ltd. INDIA, and is blended with $\gamma-\mathrm{Al}_{2} \mathrm{O}_{3}$ nanoparticles to get a homogeneous mixture of matrix and reinforcement. The Al-Si alloy powder is $60-70 \mu \mathrm{m}$
Average Particle Size (APS) and purity of $99.99 \%$ and

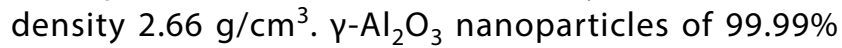
purity; $20 \mathrm{~nm}$-APS and density $3.95 \mathrm{~g} / \mathrm{cm}^{3}$ is used as reinforcement and is mechanically alloyed in $\mathrm{Al}-\mathrm{Si}$ alloy powder with varying $w t \%(2,4,6,8,10)$ for the synthesis of the composite sample. The powder is milled in high energy planetary ball mill with silicon nitride jar and balls (10 mm diameter) with milling time $12 \mathrm{~h} ; 240 \mathrm{rpm}$; ball to powder ratio 10:1. Ethanol is used as the process control additive and the milling process is stopped after $2 \mathrm{~h}$ of milling, so as to prevent sticking of material on vial boundaries. Cold welding and fracturing of material are the two processes that are involved in the mechanical milling/blending. In cold welding the reinforcement particles are wrapped up into the matrix powder, while fracturing of powder again separates the reinforcement particles from the matrix material (Figs. 1, 2).

In the milling process, the powder is cold weld and fractured to get a homogeneous distribution of the reinforcement in the matrix. The continuous collision of reinforcements with the matrix eliminates defects; reduces the size and hence strengthen the bond of the matrix and reinforcements. Mechanically milled powders are then consolidated by Spark Plasma Sintering fabrication route which involves generation of plasma with resistive heat and applied load. The self-heat generated from DC on of pulse in the particles lead to the densification at low temperature in short time. Low sintering temperature and less consolidation time help in preventing chemical reaction at the matrix reinforcement interface. In this study Spark Plasma Sintering is used to fabricate the composite powder samples at $450^{\circ} \mathrm{C} ; 100^{\circ} \mathrm{C}$ heating rate; 10 min dwell time; $50 \mathrm{MPa}$ applied load; argon atmosphere in a graphite die of $30 \mathrm{~mm}$ diameter. After cooling the sintered sample is removed from the graphite die and then grinding is done on the Silicon Carbide emery paper followed by diamond paste/aerosol spray polishing on velvet paper to get the final mirror-polished samples (Table 1).

To prepare the lubricating oil with nano additive and surfactant ( $0.5 \mathrm{wt} \%$ GNP and $0.5 \mathrm{wt} \%$ Oleic Acid) is added to the base PAO-4 lubricating oil. The nano-additive and surfactant first stirred in a magnetic stirrer for $2 \mathrm{~h}$ at controlled temperature. After that the suspension of GNP and Oleic Acid is than ultrasonically mixed with the lubricating oil for $8 \mathrm{~h}$ at $40^{\circ} \mathrm{C}$ and $40 \mathrm{kHz}$ frequency. Considering the problem of stable dispersion Oleic acid is added to the base lubricant. The oleic acid present in the lubricating oil improves the dispersion stability of the nano-additives in the lubricating oil and avoid agglomeration and clustering mechanism in the base lubricant. 

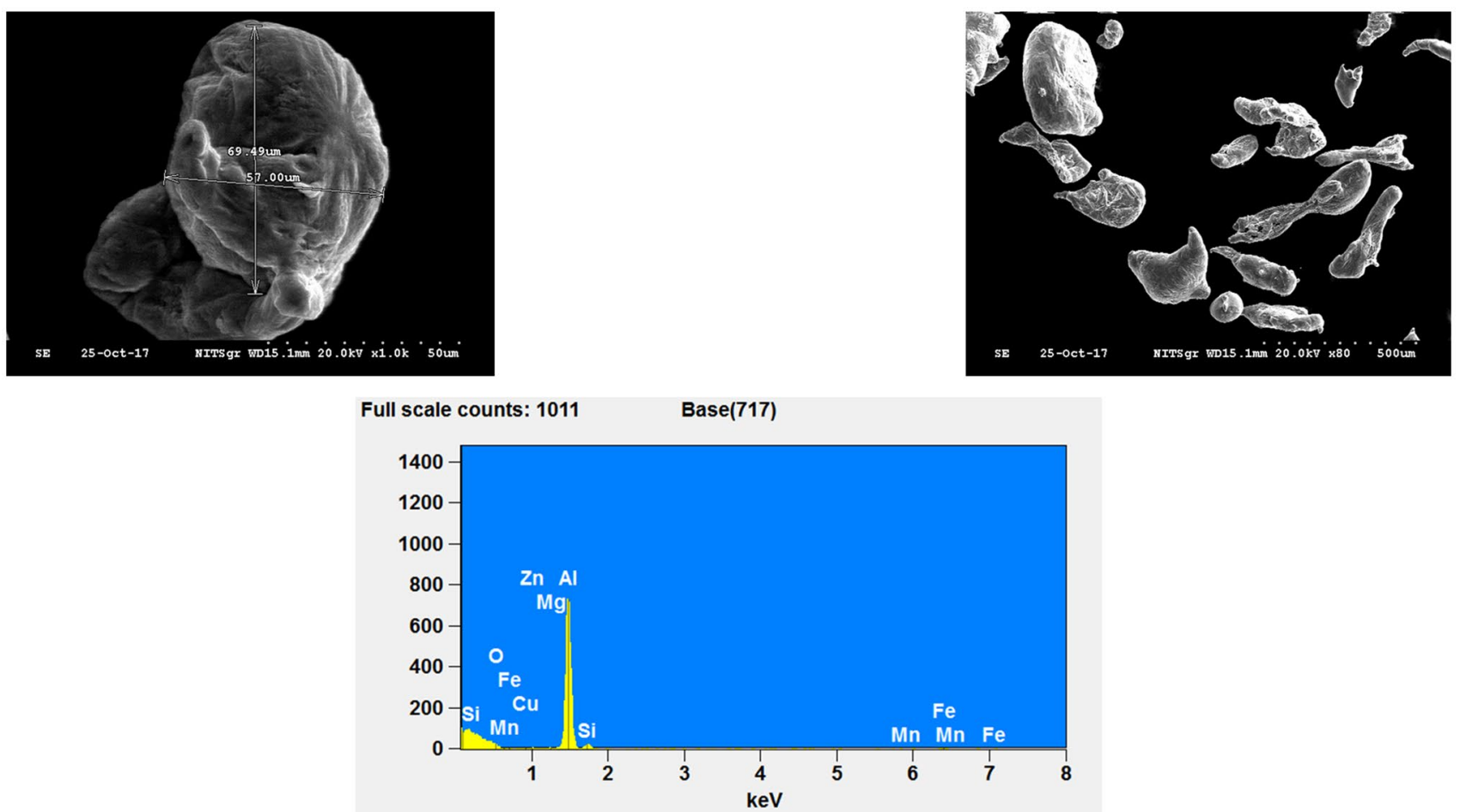

Fig. 1 Base Composition [Eutectic Al-Si alloy powder]

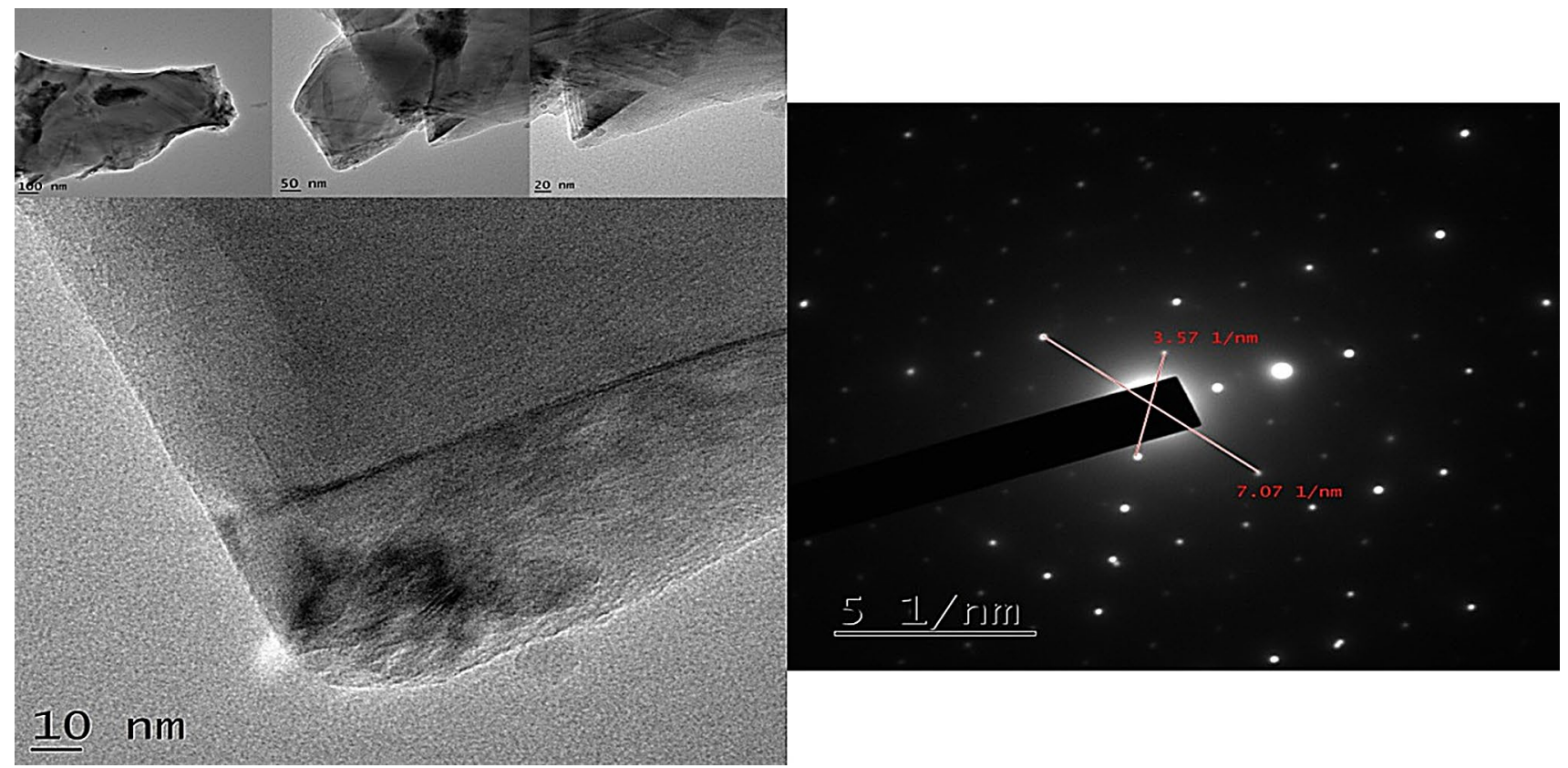

Fig. 2 TEM Images of $\mathrm{\gamma}-\mathrm{Al}_{2} \mathrm{O}_{3}$

\subsection{Tribological test and characterization}

Dry sliding tribological tests are conducted in Room Temperature (RT) conditions. R-Tech universal tribometer is used with a reciprocating ball on disc configuration. The tribometer setup is sensor-controlled and is having data acquisition system software which can be used to execute the tribotesting, measure and record the

\section{SN Applied Sciences}


Table 1 Theoretical and practical density comparison with respect to reinforcement weight percentage

\begin{tabular}{llll}
\hline $\begin{array}{l}\text { Composition (rein- } \\
\text { forcement wt\%) }\end{array}$ & $\begin{array}{l}\text { Theoretical } \\
\text { density }(\mathrm{g} / \\
\left.\mathrm{cm}^{3}\right)\end{array}$ & $\begin{array}{l}\text { Practical } \\
\text { density }(\mathrm{g} / \\
\left.\mathrm{cm}^{3}\right)\end{array}$ & $\begin{array}{l}\text { Relative } \\
\text { density \% }\end{array}$ \\
\hline $\begin{array}{l}\text { Base Composition } \\
{[\mathrm{Al}-\mathrm{Si}]}\end{array}$ & 2.66 & 2.65 & 99.62 \\
$\begin{array}{l}\text { Composition } 1 \\
{\left[\mathrm{Al}-\mathrm{Si}+2 \mathrm{wt} \% \mathrm{Al}_{2} \mathrm{O}_{3}\right]}\end{array}$ & 2.68 & 2.654 & 99.02 \\
$\begin{array}{l}\text { Composition 2 } \\
{\left[\mathrm{Al}-\mathrm{Si}+4 \mathrm{wt} \% \mathrm{Al}_{2} \mathrm{O}_{3}\right]}\end{array}$ & 2.712 & 2.666 & 98.30 \\
$\begin{array}{l}\text { Composition } 3 \\
{\left[\mathrm{Al}-\mathrm{Si}+6 \mathrm{wt} \% \mathrm{Al}_{2} \mathrm{O}_{3}\right]}\end{array}$ & 2.737 & 2.691 & 98.31 \\
$\begin{array}{l}\text { Composition 4 } \\
{\left[\mathrm{Al}-\mathrm{Si}+8 \mathrm{wt} \% \mathrm{Al}_{2} \mathrm{O}_{3}\right]}\end{array}$ & 2.763 & 2.7 & 97.71 \\
$\begin{array}{l}\text { Composition } 5 \\
{\left[\mathrm{Al}-\mathrm{Si}+10 \mathrm{wt} \% \mathrm{Al}_{2} \mathrm{O}_{3}\right]}\end{array}$ & 2.789 & 2.51 & 89.99 \\
\hline
\end{tabular}

variations in the COF. Analysis of the varying load and sliding distance on the COF and wear coefficient of the composite is measured. The load test is carried out for the load varying from 10 to $80 \mathrm{~N}$ with other parameters i.e. stroke $2 \mathrm{~mm}$; frequency $30 \mathrm{~Hz}$; sliding distance $120 \mathrm{~m}$ with sliding velocity of $0.120 \mathrm{~m} / \mathrm{s}$. sliding distance test is conducted from $450 \mathrm{~m}$ in five equal intervals $(90 \mathrm{~m}$, $180 \mathrm{~m}, 270 \mathrm{~m}, 360 \mathrm{~m}, 450 \mathrm{~m}$ ) with load $20 \mathrm{~N}$ and rest other parameters remain same. Chrome steel plated with chromium is used as the counter body to perform the reciprocating ball on disc tribotest. To calculate wear volume 3D-Surface Profilometer is used and to calculate wear coefficient Eq. (1) is used:
$W r=\frac{W v}{S D \times L}$

Wr wear coefficient; Wv wear volume; SD sliding distance; $L$ load.

Each time after and before the tribological test the samples as well as the counter ball is cleaned in acetone using an ultrasonic cleaner followed by drying in the vacuum oven. After the testing the cleaned sample undergoes various characterizations techniques to study the wear of the material using optical microscopy; SEM; EDS and 3D surface profilometer (Fig. 3).

In previous studies, various researchers reported that the microstructural properties directly influenced the material mechanical as well as tribological properties. Mondal et al. [29] in their microstructural investigation reported that the uniform distribution of the reinforcement is important to have desired properties. Chawla and Chawla [30] in their studies reported that the uniform and homogeneous distribution; clean microstructure is important to have good properties of the composites. Kok et al. [31] in their study report certain variables i.e. reinforcement type; size; mode of incorporation of reinforcement that affects the uniformity and homogeneity of the composite's materials.

In the present study microstructural and surface characterization techniques are used for pre microstructural analysis. It is reported that the uniform distribution is achieved up to $6 \mathrm{wt} \%$ of reinforcement, for increasing reinforcement $w t \%$ there is some agglomeration and clustering of reinforcement in the composite surface. An increase in the reinforcement leads to the clustering

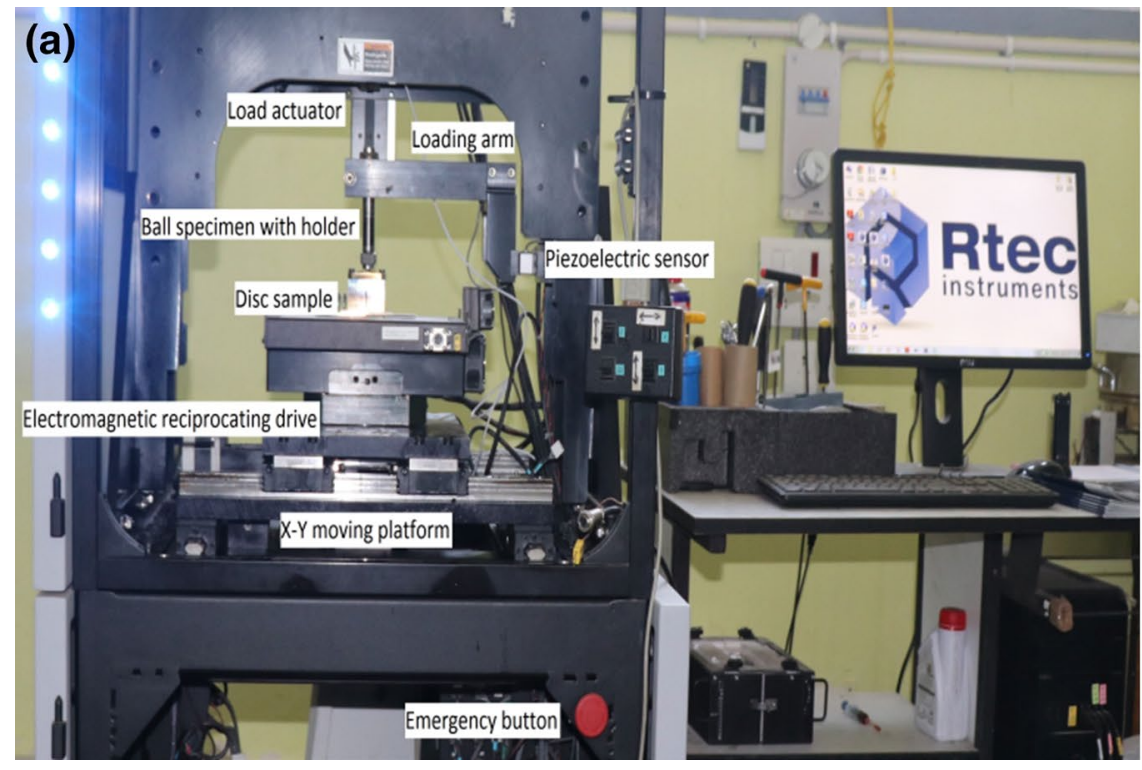

(b)

Fig. 3 a Universal reciprocating ball-on-disc tribometer. b Schematic of diagram ball-on-disc

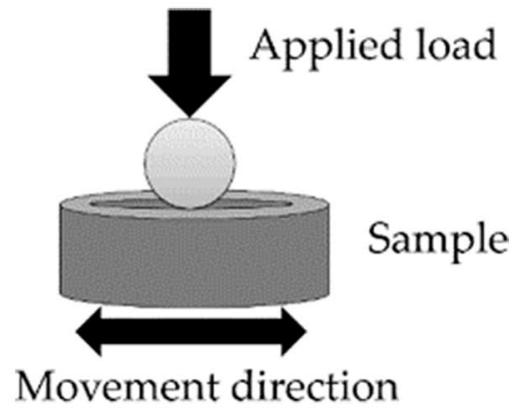


in some area zones. Good bonding is observed but some pores and voids are also observed for $10 \mathrm{wt} \%$ composite sample which might be the reason for lower relative density for $10 \mathrm{wt} \%$ reinforcement sample. The reason that affects the particle segregation may be because of the Aluminum dendrites which solidify first, so rejection of the particles by solid-liquid interface hence segregated. Due to mechanical milling plastic strain in the grains will be less which leads to the ripening/coarsening effect. The ripening leads to reduction in the surface area and spheroidal morphology is obtained. It is observed that no other phase is formed (Aluminum Carbide $\mathrm{Al}_{4} \mathrm{C}_{3}$ ) while fabrication, as in the Spark Plasma Sintering fabrication process low temperature with fast sintering is done which does not support phase transformation while fabrication. The presence of $\mathrm{Al}_{4} \mathrm{C}_{3}$ is reported by various other researchers in the past investigation as it deteriorates the composite properties. 3-D surface profilometer of the polished sample is done so as to measure Ra value shown in Fig. 7. The average roughness value $(\mathrm{Ra})$ for the composite material sample is $0.008 \mu \mathrm{m}$ and $0.004 \mu \mathrm{m}$ for the counter body surface roughness (Fig. 4).

\section{Results}

\subsection{Effect of load and sliding distance}

Room temperature dry and wet condition tribological tests are conducted to study friction behavior and wear behavior of SPS fabricated samples against chromiumplated chrome steel ball on a ball on disc universal reciprocating tribometer. COF versus load and sliding distance for different compositions samples at dry conditions shown in Fig. 5a, b. Wear volume for variable
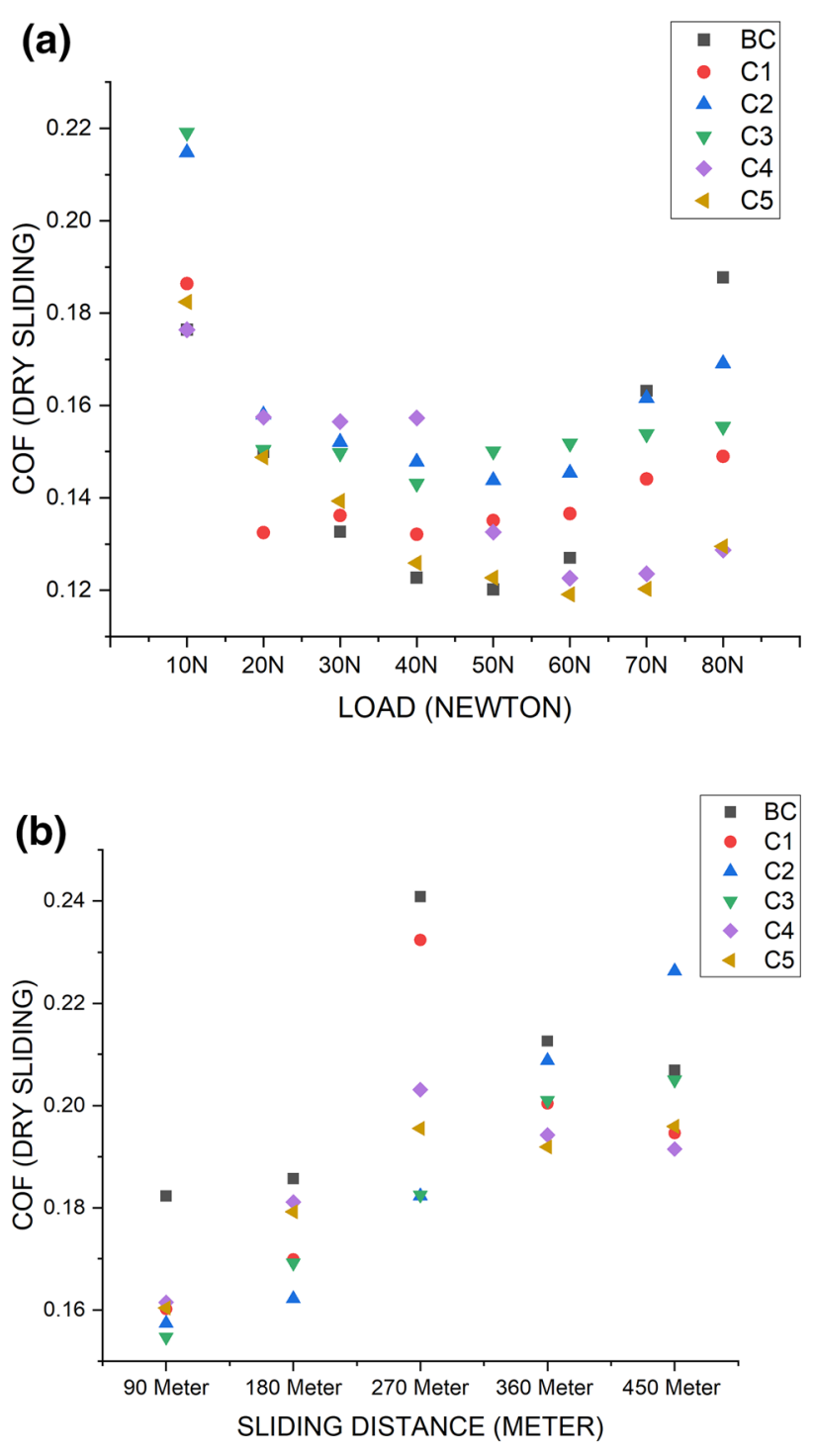

Fig. 5 a COF v/s Load for dry sliding. b COF v/s Sliding Distance for dry sliding
Fig. 4 3-D surface profilometer of mirror-polished composite surface

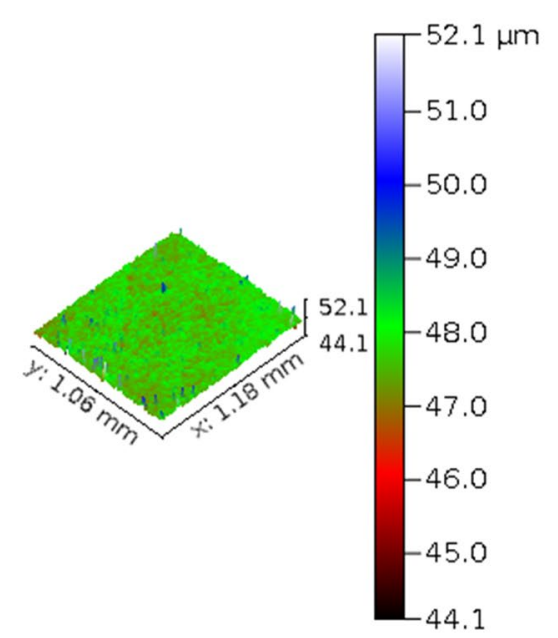



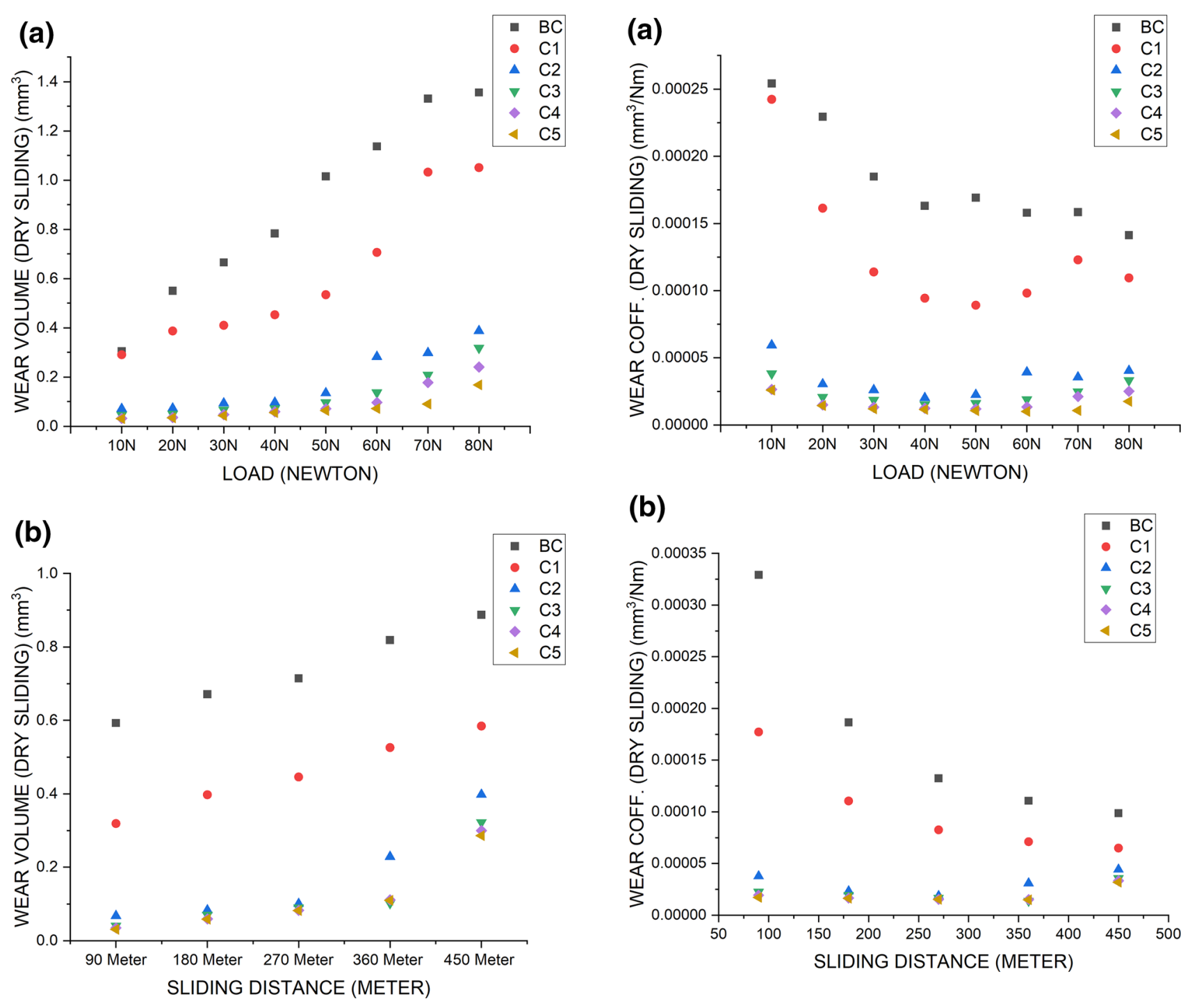

(b)

Fig. 6 a Wear Volume v/s Load for dry sliding. b Wear Volume v/s Sliding Distance for dry sliding

load and sliding distance under dry conditions shown in Fig. $6 a$, b respectively. The wear Coefficient graph vs load and sliding distance are shown in Fig. 7a, b. It is observed that, for base composition, the COF first decreases as the load increases from $10 \mathrm{~N}-50 \mathrm{~N}$ load and then again starts to increase. The maximum value for the COF is obtained at $80 \mathrm{~N}$ load (0.1877) and the minimum value is at $50 \mathrm{~N}$ load (0.1202). Wear volume for base composition linearly increases with load. Maximum $\left(1.35601 \mathrm{~mm}^{3}\right)$ and Minimum $\left(0.30509 \mathrm{~mm}^{3}\right)$ wear volume is reported at $80 \mathrm{~N}$ and $10 \mathrm{~N}$ load respectively. Wear coefficient for base composition gradually decrease with increasing load. Maximum $\left(0.00025424 \mathrm{~mm}^{3} / \mathrm{Nm}\right)$ and minimum $\left(0.000141251 \mathrm{~mm}^{3} / \mathrm{Nm}\right)$ wear coefficients are obtained at load $10 \mathrm{~N}$ and $80 \mathrm{~N}$ load respectively.

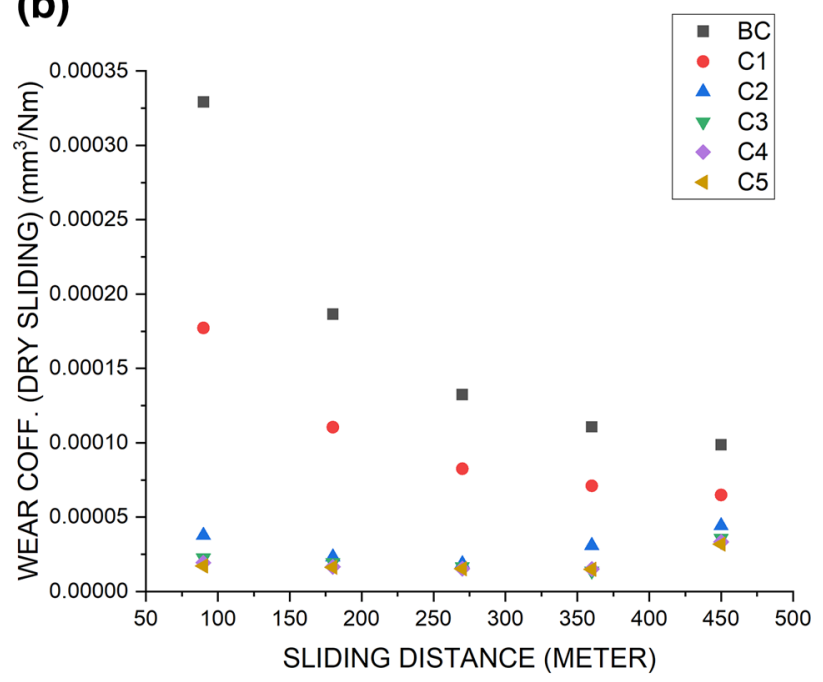

Fig. 7 a Wear Rate v/s Load for dry sliding. b Wear Rate v/s Sliding Distance for dry sliding

Composition 1 shows similar trend as base composition for wear volume but comparatively less wear volume is reported. The wear coefficient for Composition 1 shows a decreasing trend with increasing load. For composition 2 there is continuous decrease in COF from $10 \mathrm{~N}$ - $60 \mathrm{~N}$ load, and then again increases. The wear volume for Composition 2 increases as load increases but a significant reduction in the wear volume is reported for this composition compared to earlier one. In composition 3, the trend for COF is first Continuous decrease up to $40 \mathrm{~N}$ load (0.1431) and further increase as the load increases. For composition 4, Decrement in COF is reported up to $60 \mathrm{~N}$ load from $10 \mathrm{~N}$ afterward COF further start increasing. Liner decrement in the COF for Composition 5 is reported from 10 to $60 \mathrm{~N}$ load and then again increases. For composition $5\left(0.16829 \mathrm{~mm}^{3}\right)$ maximum 
and $\left(0.03115 \mathrm{~mm}^{3}\right)$ minimum wear volume is obtained at $10 \mathrm{~N}$ and $80 \mathrm{~N}$ load. In case of composition 5 maximum wear coefficient $\left(2.59555 \mathrm{E}-05 \mathrm{~mm}^{3} / \mathrm{Nm}\right)$ at $10 \mathrm{~N}$ whereas, minimum wear coefficient $\left(1.00324 \mathrm{E}-05 \mathrm{~mm}^{3}\right.$ / $\mathrm{Nm})$ at $60 \mathrm{~N}$ load is observed. The COF behavior of all the composite samples shows the similar trend of first decrease up to certain load limit and then increase for the dry sliding conditions. This behavior is attributed to the load bearing capacity as well as nano-scale asperities-asperities interlocking mechanism. The increment of $\mathrm{n}-\mathrm{Al}_{2} \mathrm{O}_{3}$ reinforcement in the matrix material improves the load bearing capacity of the composite sample thus helps in reducing the COF value up to certain load limit. As this load limit exceeds, it will affect the load bearing capacity of the composite leads to increase in the asperities-asperities interlocking at the nano-scale. This leads to increase in the COF value after a certain load limit.

Sliding Distance test $(90-450 \mathrm{~m})$ is performed in five equal steps in this study with other parameters i.e. frequency $30 \mathrm{~Hz}$; load $10 \mathrm{~N}$; stroke $2 \mathrm{~mm}$ constant. COF for base composition under dry sliding conditions increase up to $270 \mathrm{~ms}$ and afterward decreases. Maximum (0.2409) and minimum (0.1823) COF is observed at sliding distance $270 \mathrm{~m}$ and $90 \mathrm{~m}$ respectively. For base composition, wear volume linearly increases with sliding distance. Maximum $\left(0.88756 \mathrm{~mm}^{3}\right)$ and Minimum $\left(0.59278 \mathrm{~mm}^{3}\right)$ wear volume is reported at $450 \mathrm{~m}$ and $90-\mathrm{m}$ sliding distance respectively. The maximum Wear coefficient for base composition $\left(0.000329324 \mathrm{~mm}^{3} / \mathrm{Nm}\right)$ is obtained at $90-\mathrm{m}$ sliding distance and minimum $\left(9.86175 \mathrm{E}-05 \mathrm{~mm}^{3} / \mathrm{Nm}\right)$ wear coefficient is obtained at $450-\mathrm{m}$ sliding distance. For composition 1 there is continuous increase in COF from 90 to $270 \mathrm{~m}$, and then a decrease in COF is observed for $360 \mathrm{~m}$ and $450 \mathrm{~m}$. Liner increment in wear volume trend is reported for Composition 1. A linear increase in the COF with sliding distance is reported for composition 2. Composition 2 wear volume increases with increasing sliding distance. For composition 3 linear increments in the COF with increasing sliding-distance is reported. Liner increment in COF for Composition 4 is reported up to $270 \mathrm{~m}$. Composition 4 shows similar trend as previous compositions, with linearly increases in wear volume as sliding distance increases. For Composition 5, a continuous increase in the COF is observed up to 270-m distance after that the valve fluctuates. The maximum value of COF is reported (0.1959) at $450 \mathrm{~m}$ and minimum value $(0.1604)$ is reported at $90 \mathrm{~m}$. Wear volume for composition 5 shows $\left(0.2862 \mathrm{~mm}^{3}\right)$ maximum and $\left(0.03077 \mathrm{~mm}^{3}\right)$ minimum value at $90 \mathrm{~m}$ and $450 \mathrm{~m}$. In case of composition 5 maximum wear coefficient $\left(3.18004 \mathrm{E}-05 \mathrm{~mm}^{3} / \mathrm{Nm}\right)$ at $450 \mathrm{~m}$ whereas minimum wear coefficient $\left(1.48319 \mathrm{E}-05 \mathrm{~mm}^{3}\right.$ / $\mathrm{Nm}$ ) is reported at 360-meters sliding distance. From the dry sliding distance test it is observed that the COF value for all the composites constantly increases up to $270 \mathrm{~m}$ or $360 \mathrm{~m}$ after that the a stabilization in the increasing COF value is achieved. This behavior of first increase and then stabilize or decreased value is attributed to the high asperities contact in the initial run-in-period, which indeed increases the wear volume in the initial sliding distance leads to increases initial COF. These protruded wear debris then get plastically deformed due to continuous sliding and formed a mechanical mixed layer (MML) on the wear scar zone. This MML provides a self-lubrication junction on the wear scar stabilizes the COF value and causes easy sliding compared to initial run-in-period.

However for the lubricating tribological test, it is clear that $\mathrm{n}-\mathrm{Al}_{2} \mathrm{O}_{3}$ as the reinforcement in the $\mathrm{Al}-\mathrm{Si}$ matrix material as well as inclusion of GNP as nano-additive and Oleic acid as surfactant for stable and proper dispersion has strong impact on the COF and wear reduction of the composite sample. The friction test on the composite samples are performed for four different lubricants i.e. PAO-4 base lubricant oil, SAE20W50 commercial engine oil, PAO-4 + 0.5 wt $\%$ GNP, PAO-4 + $0.5 w t \%$ GNP + $0.5 w t \%$ Oleic Acid (OA). The best results for the COF are achieved for $\mathrm{Al}-\mathrm{Si}+10 \mathrm{wt} \% \mathrm{n}-\mathrm{Al}_{2} \mathrm{O}_{3}$ with PAO-4 + $0.5 \mathrm{wt} \%$ GNP + 0.5 wt\% OA lubricating oil. It is reported that for the PAO-4 base oil and SAE20W50 lubricating oil the COF behavior remain the same shown in Fig. $8 a$, b. The COF for the composite sample decrease with the increase in the load from $10 \mathrm{~N}$ to $50 \mathrm{~N}$, afterward there is a slight increase in the COF with increasing load from $60 \mathrm{~N}-80 \mathrm{~N}$. This reduction in the COF is attributed to the coherent oil film between the interface which also bears the load up to certain limit and reduces the COF value. As the load increases the load bearing capacity of the lubricating oil decreases which leads to asperity contact at the interface indeed increases the COF value after a limit. For PAO- $4+0.5 \mathrm{wt} \%$ GNP nano lubricating oil the COF gradually decreases with increasing load is shown in Fig. 8c. This gradual decrease in the COF is attributed to the addition of GNP nano additive in the lubricating oil which provides the self-lubricating effect as well as increases the load bearing capacity compared to base lubricating oil. The GNP nano additive are having lamellar structure with weak Vander wall force which cause easy shearing and helps in easy sliding at the tribo interface. The nano additive present in the lubricating oil settle down in the asperities of the sliding interface reduces the valleys surface roughness which help in reducing the frictional traction ultimately reduces the COF. Another possible mechanism is the ball bearing lubrication mechanism of the nano additives which convert the pure sliding motion to the rolling motion of the sliding interface reduces the COF. Tribo test results for PAO- $4+0.5$ wt $\%$ GNP + 0.5 wt $\%$ OA lubricating oil for composite samples is represented in Fig. $8 \mathrm{~d}$. Excellent friction 

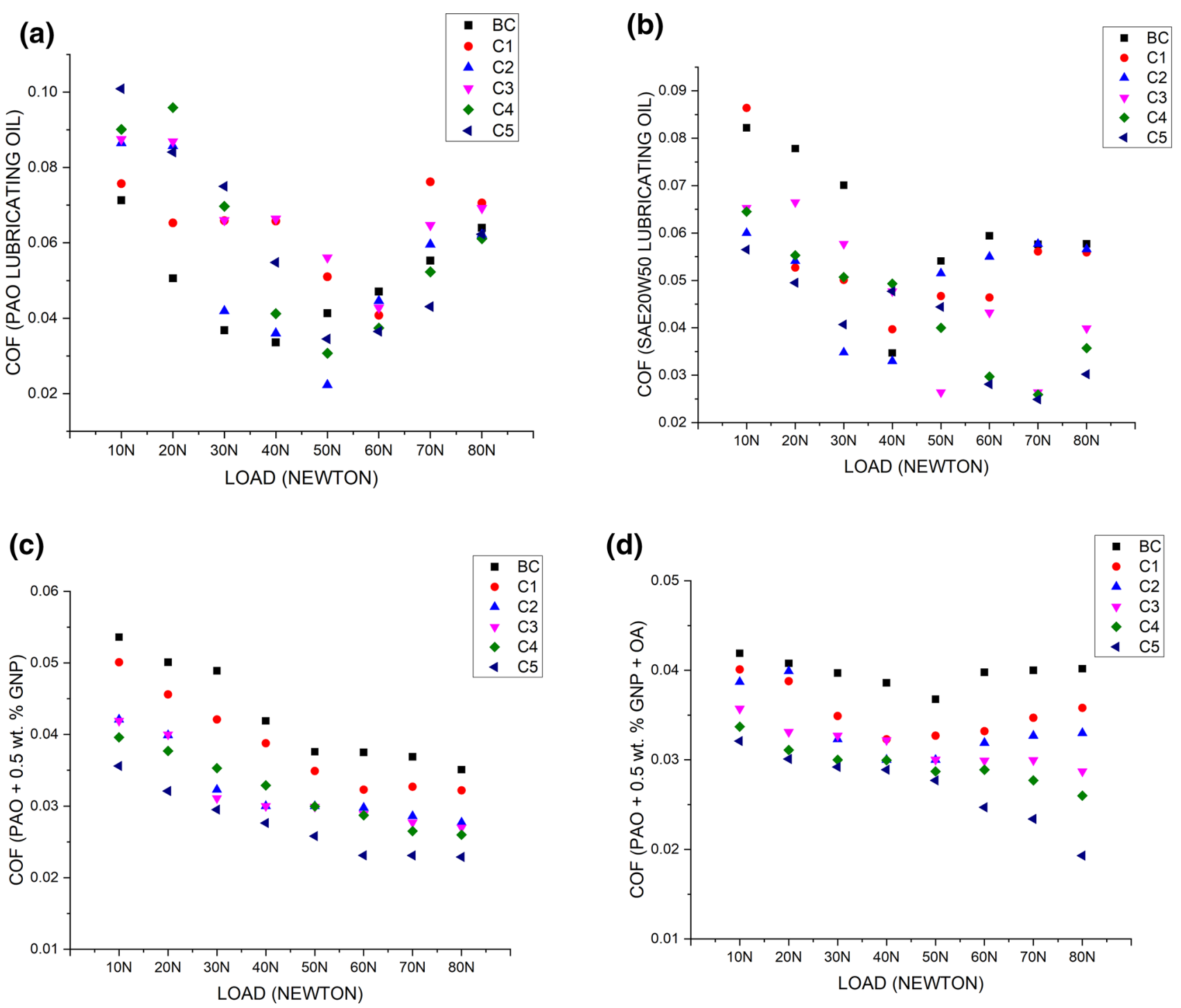

Fig. 8 a COF v/s Load for PAO-4 oil. b COF v/s Load for SAE20W50 oil. c COF v/s Load for PAO-4+0.5 wt\% GNP. d COF v/s Load for PAO-4 + 0.5 wt $\%$ GNP + $0.5 w t \%$ OA

behavior is represented for this tribo-test. From the results it is observed that the COF continuously decreases with the increasing load $(10 \mathrm{~N}-80 \mathrm{~N})$. The minimum COF 0.0193 value is attained for $\mathrm{Al}-\mathrm{Si}+10 \mathrm{wt} \% \mathrm{n}-\mathrm{Al}_{2} \mathrm{O}_{3}$ composite sample at $80 \mathrm{~N}$ load. The reduction in the COF is attributed to the nano additive GNP and OA which is used as the surfactant. OA present in the lubricating oil improves the dispersion stability of the nano additive in the lubricating oil. As agglomeration and clustering of the nano additives is a major problem which effect the tribological performance of the nano additive in the lubricating oil. OA reduces the settling behavior of the nano additives particles that helps in improving the frictional performance of the lubricating oil with nano additives. Mending mechanism, polishing mechanism as well as roll ball bearing mechanism are attributed to the reduction in COF value. The nano particles present in the lubricating oil get deposited in the asperities of the interface reduces the COF. The polish and ball bearing effect helps not only to provide easy sliding but also improves the load bearing capacity of the lubricating oil which helps to attain the minimum COF even at high loading conditions.

For sliding distance test with PAO-4 and SAE20W50 lubricating oil the COF value for the increasing sliding distance is shown in Fig. 9a, b. COF for the base composition goes on increasing with increasing sliding distance. This increase in the COF is attributed to the soft $\mathrm{Al}-\mathrm{Si}$ alloy matrix base composition sample which easily protrude from the interface increases the surface roughness at nano scale (increased asperity-asperity contact) which 

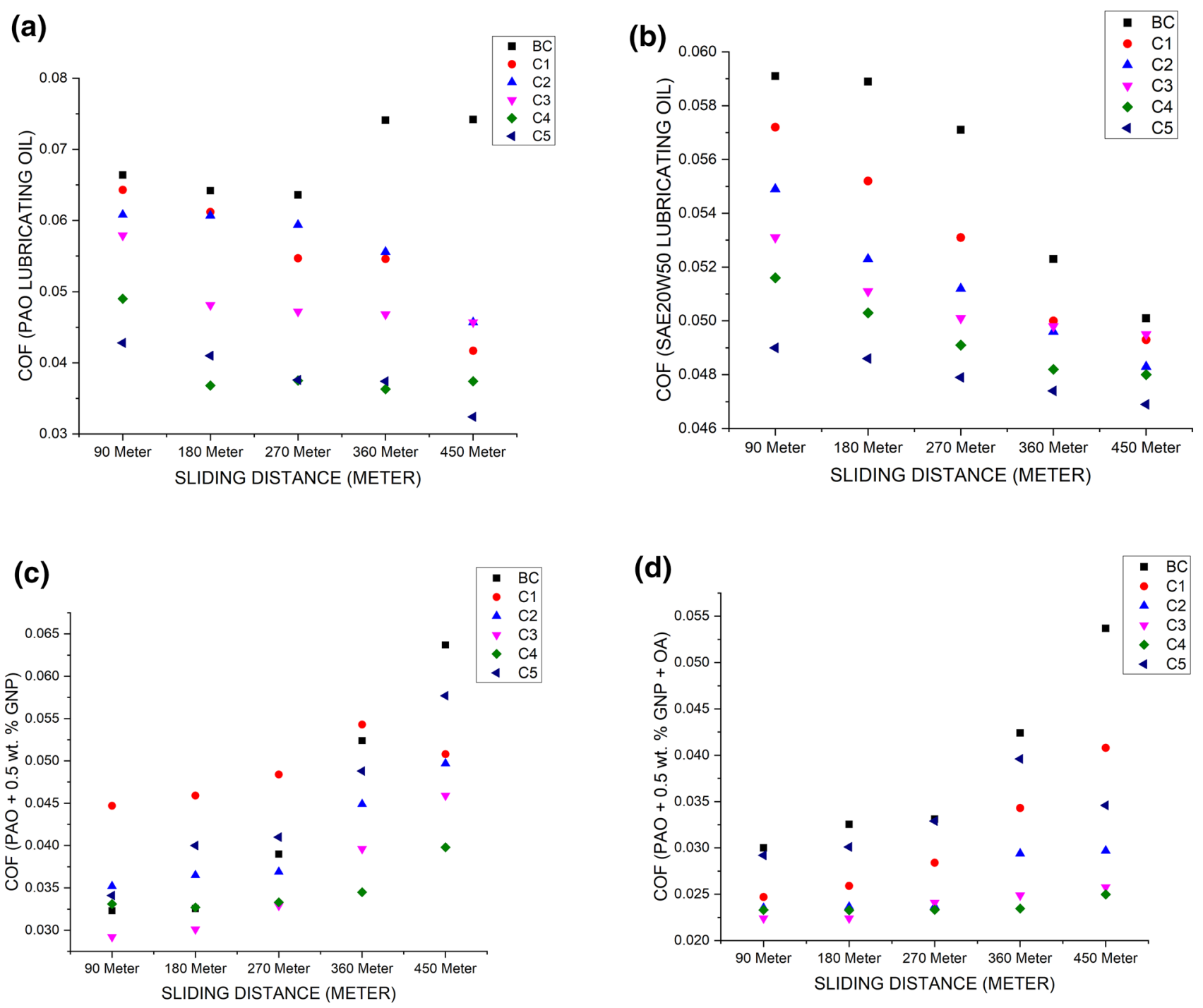

Fig. 9 a COF v/s Sliding Distance for PAO-4 oil. b COF v/s Sliding Distance for SAE20W50 oil. c COF v/s Sliding Distance for PAO-4+0.5 wt\% GNP. d COF v/s Sliding Distance for PAO-4 + 0.5wt $\%$ GNP + 0.5wt $\%$ OA

causes the asperities interlocking leads to increase COF with the sliding distance. For composite sample the COF first increases for initial sliding distance, afterward attain a steady state value with PAO-4 and SAE20W50 lubricating oil. This friction behavior is attributed to the protruded particles that increases the COF for the run-in-period sliding distance. After continuous sliding the COF attained steady state value which is because of the $\mathrm{n}-\mathrm{Al}_{2} \mathrm{O}_{3}$ reinforcements which is also considered to be an effective catalyst which helps in formation of the smooth oxide adsorbed layer on the wear scar after some time of continuous sliding which leads to further attain steady stable value of COF instead of further increasing. For PAO- $4+0.5 \mathrm{wt} \% \mathrm{GNP}$ sliding distance test the COF value for the composite sample increases for the initial sliding distance and then attain a steady state value, shown in Fig. 9c. This steady state value is attributed to the formation of adsorbed Graphene oxide smooth protective film layer on the tribo surface thus helps in attained steady state value of COF. For PAO- $4+0.5$ wt $\%$ GNP + 0.5 wt $\%$ Oleic Acid sliding distance test a steady state vale is obtained from the testing is shown in Fig. 9d. This stable value is attributed to the formation of low shear stress lubrication junction of oxide layer which increases the smoothness of the sliding surface and cause easy sliding at the interface thus stabilize the COF for the increasing Sliding Distance.

Wear volume with different lubricating oils (PAO-4 base lubricant oil, SAE20W50 commercial engine oil, PAO- $4+0.5 w t \%$ GNP, PAO-4 + $0.5 w t \%$ GNP + $0.5 w t \%$ Oleic Acid (OA) for composite samples are shown in Fig. 10a-h respectively. Increase in the wear volume trends are observed with all the lubricating oil 

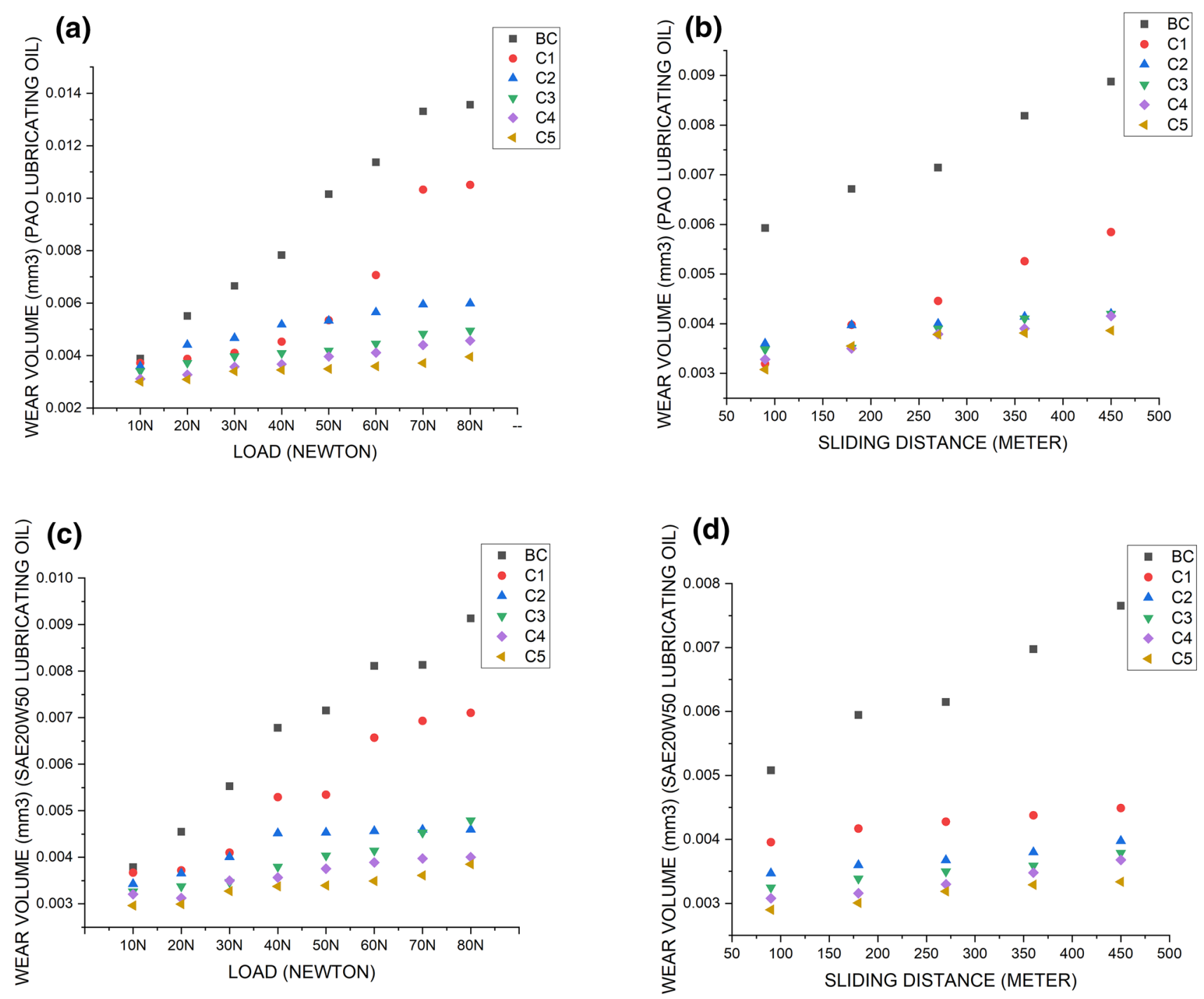

Fig. 10 a Wear Volume v/s Load for PAO-4 oil. b. Wear Volume v/s Sliding Distance for PAO-4 oil. c Wear Volume v/s Load for SAE20W50 oil. d Wear Volume v/s Sliding Distance for SAE20W50 oil. e Wear Volume v/s Load for PAO-4+0.5 wt\% GNP. f Wear Volume

v/s Sliding Distance for PAO-4+0.5 wt\% GNP. g Wear Volume v/s Load for PAO-4+ 0.5 wt $\%$ GNP 0.5 wt $\%$ OA. h Wear Volume v/s Sliding Distance for PAO-4 + 0.5 wt $\%$ GNP + 0.5 wt $\%$ OA

on the fabricated samples. Best wear resistance results are observed for the PAO- $4+0.5 \mathrm{wt} \%$ GNP and PAO-4 + $0.5 w t \%$ GNP + $0.5 w t \%$ OA lubricating oil. It is also observed that the inclusion of the hard-phase ceramic reinforcements in the composite sample also increases the wear resistance of the fabricated sample. To calculate the wear coefficient Eq. 1 with input variable such as sliding distance, load and wear volume are used. The results for the wear coefficient under different lubricants PAO-4 base lubricant oil, SAE20W50 commercial engine oil, PAO- $4+0.5 w t \%$ GNP, PAO- $4+0.5 w t \%$ GNP + 0.5 wt $\%$ Oleic Acid (OA) for the fabricated composite samples are represented in Fig. 11a-h respectively.

\section{Discussion}

\subsection{Wear analysis}

Dry sliding wear of the aluminum alloy-based composite is the function of the applied load. At low load, wear mechanisms such as oxidation; tribo-layer formation; plastic deformation are the prominent one, at high load adhesion and 3-body abrasion are the dominated wear mechanisms. The reinforcement also plays an important role in reduced wear as they act as a load-bearing element. Another crucial factor that affects wear behavior 

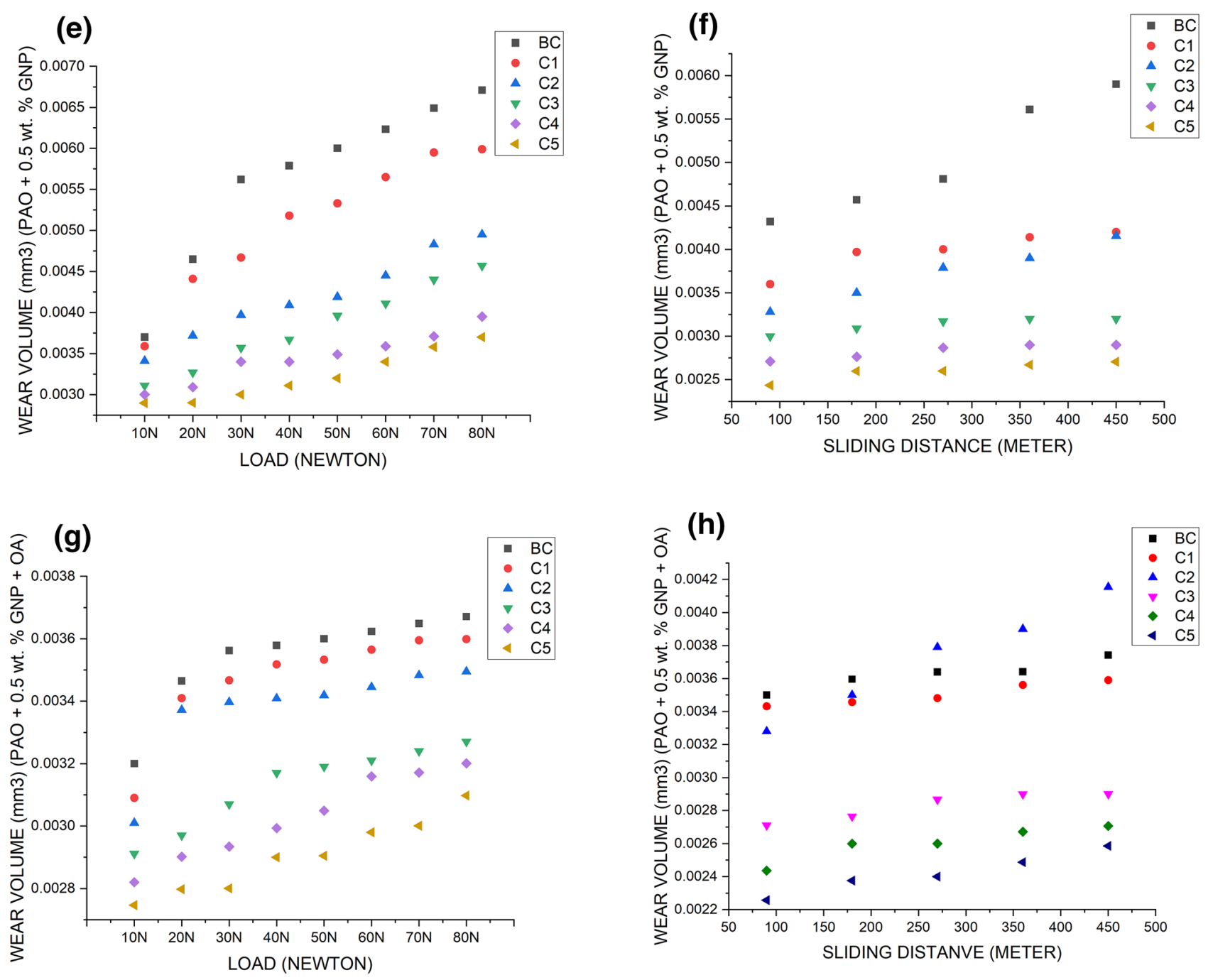

Fig. 10 (continued)

of the material is fracture toughness. A new wear regime starts, when the load magnitude is higher than fracture strength of the reinforcement particles. In this wear regime matrix material and the counting body is in direct contact which leads to predominant delaminating wear mechanism. At high load, the wear of the material is associated with high solubility which leads to high degree adhesion on the counter body. Transition in the wear phase from mild to severe wear is also the function of sliding speed, distance as well as temperature. At low-speed material surface exhibit low wear coefficient and stable tribo-layer which indeed significantly reduce direct metal-metal contact. At high speed, the tribolayer break down due to thermal softening exceeding the frictional traction leads to higher wear coefficient. Friction induced temperature generated due to frictional heat also dominate wear in case of high load and sliding speed.

Optical and SEM micrographs studies shown in Figs. 12 and 13 are done on the composite samples. It is observed that composite containing alumina particles show high fracture toughness because of hard phase reinforcement. Three main wear mechanisms are identified for the tribopair. For initial loading (low load) abrasive wear is observed for run-in-period. For low load with continuous sliding distance, there is a transition in the wear mechanism from abrasion to discontinuous oxidation layer formation. The oxide layer/tribo-layer is attributed to the rise in the contact surface temperature with increasing sliding distance. With further increase in the temperature transition in the wear regime takes place from mild wear to severe wear. Within this regime delaminating is the prominent 

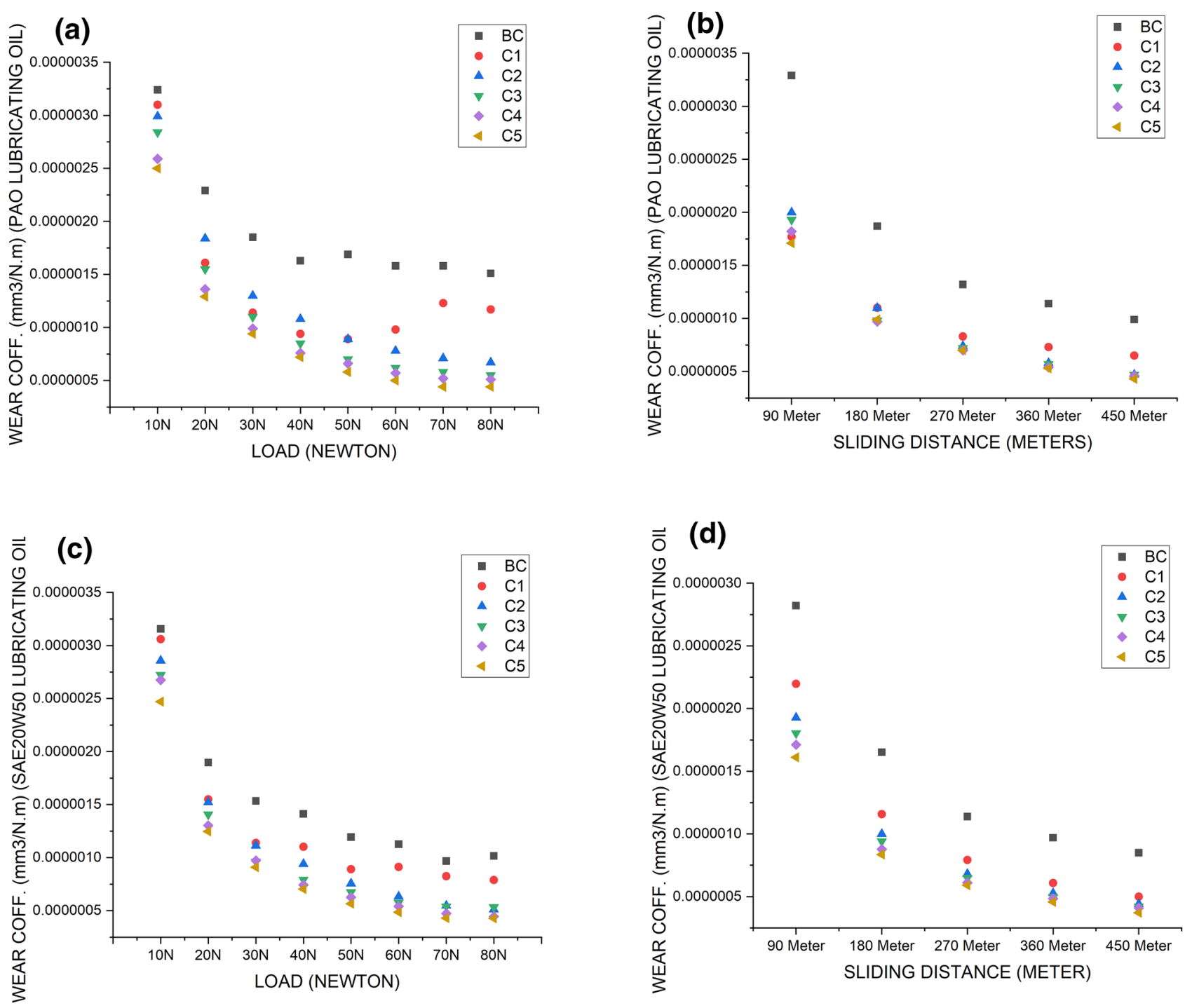

Fig. 11 a Wear Rate v/s Load for PAO-4 oil. b Wear Rate v/s Sliding Distance for PAO-4 oil. c Wear Rate v/s Load for SAE20W50 oil. d Wear Rate v/s Sliding Distance for SAE20W50 oil. e Wear Rate v/s Load for PAO-4+0.5 wt\% GNP. f Wear Rate v/s Slid-

ing Distance for PAO-4+0.5 wt\% GNP. g Wear Rate v/s Load for PAO-4+ 0.5 wt $\%$ GNP 0.5 wt $\%$ OA. h Wear Rate v/s Sliding Distance for PAO-4 + 0.5 wt $\%$ GNP + 0.5 wt. $\%$ OA

wear mechanism leads to the removal of oxidation layer. It is observed that transition in the wear from abrasive to oxidation and further oxidation to delaminating wear is reported as the function of sliding distance and applied load. Delamination pits, adhesion, abrasion wear are the prominent wear mechanisms observed by SEM and Optical micrographs in Figs. 12 and 13. Abrasion marks are clearly visible on the wear scar which gives us the evidence of the abrasion of material. SEM analysis confirms the formation of an oxide layer on the sliding interface. The presence of this oxide layer on the wear scar reduces the direct metallic contact between the asperities and therefore reduce the wear. EDS analysis confirms the transfer of material promoting adhesion wear on the wear scar zone

is shown in Fig. 14. Moreover, increase in the load as well as at higher sliding distance $(450 \mathrm{~m}$ ) increases the interface temperature. An increase in the contact temperature leads to the thermal softening of the material in subsurface zone which leads to the delamination of the oxide layer and causes the material to wear because of delaminating wear. From SEM analysis, it is observed that abrasion grooves; discontinuous oxidation layer formation, adhesion wear and delaminating pits wear are the main wear mechanisms for dry sliding conditions. 3D surface roughness studies made on the wear scar are shown in Fig. 15.

From optical and SEM micrographs on the scar zone for lubricating conditions are shown in Figs. 16 and 17 . Wear scar for the base composition observed deep rough 

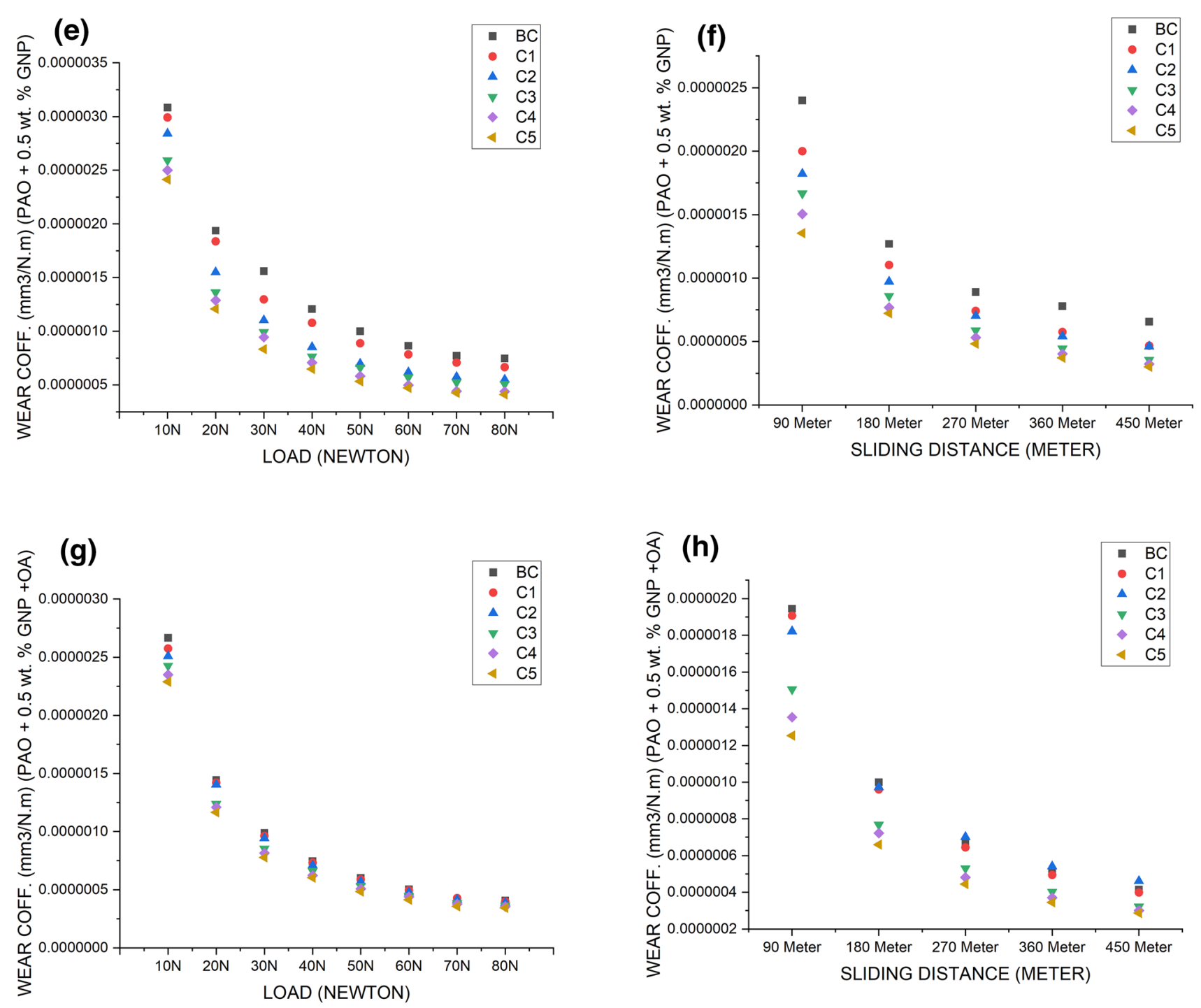

Fig. 11 (continued)

and rugged worn surface. The worn surface is dominated by two type of wear mechanisms. First is the deep rugged abrasion marks attributed to the plowing mechanism and second is delamination which is due of sever plastic deformation on the sliding interface. Delamination pits are observed on the scar surface. These wear scar morphology coincides with the high friction and wear coefficient values for the base composition under lubricating conditions. The two most important factor that mostly effect the wear of materials are chemical activities of the materials while tribo interference as well as shear modulus of the material. It is well known that high abrasion mechanism increases due to high chemical activities which decreases the shear resistance of the material. Figures 16 and 17 shows deep furrows and large exfoliation on the wear zone which is because of the reduced wear resistance for the base composition. With the inclusion of the $\mathrm{n}-\mathrm{Al}_{2} \mathrm{O}_{3}$ in the matrix base composition the plowing and abrasion mechanism reduces which indeed leads to the formation of smooth tribolayer on the sliding surface. The presence of reinforcement in the matrix material increases the hardness as well as load bearing capacity of the composite which also reduces the adhesion wear mechanism by decreasing the solubility of the counter-body and the matrix material. For composite samples tested with PAO-4 and SAE20W50 lubricating oil, grooves, rugged surface and delamination pits get lessened and discontinuous oxide film layers are observed on the worn scar surface, shown in figure. Accordingly the wear volume as well as wear coefficient reduces compared to the base composition samples. The severe furrows and deep grooves are no longer observed for the composite sample with PAO-4 

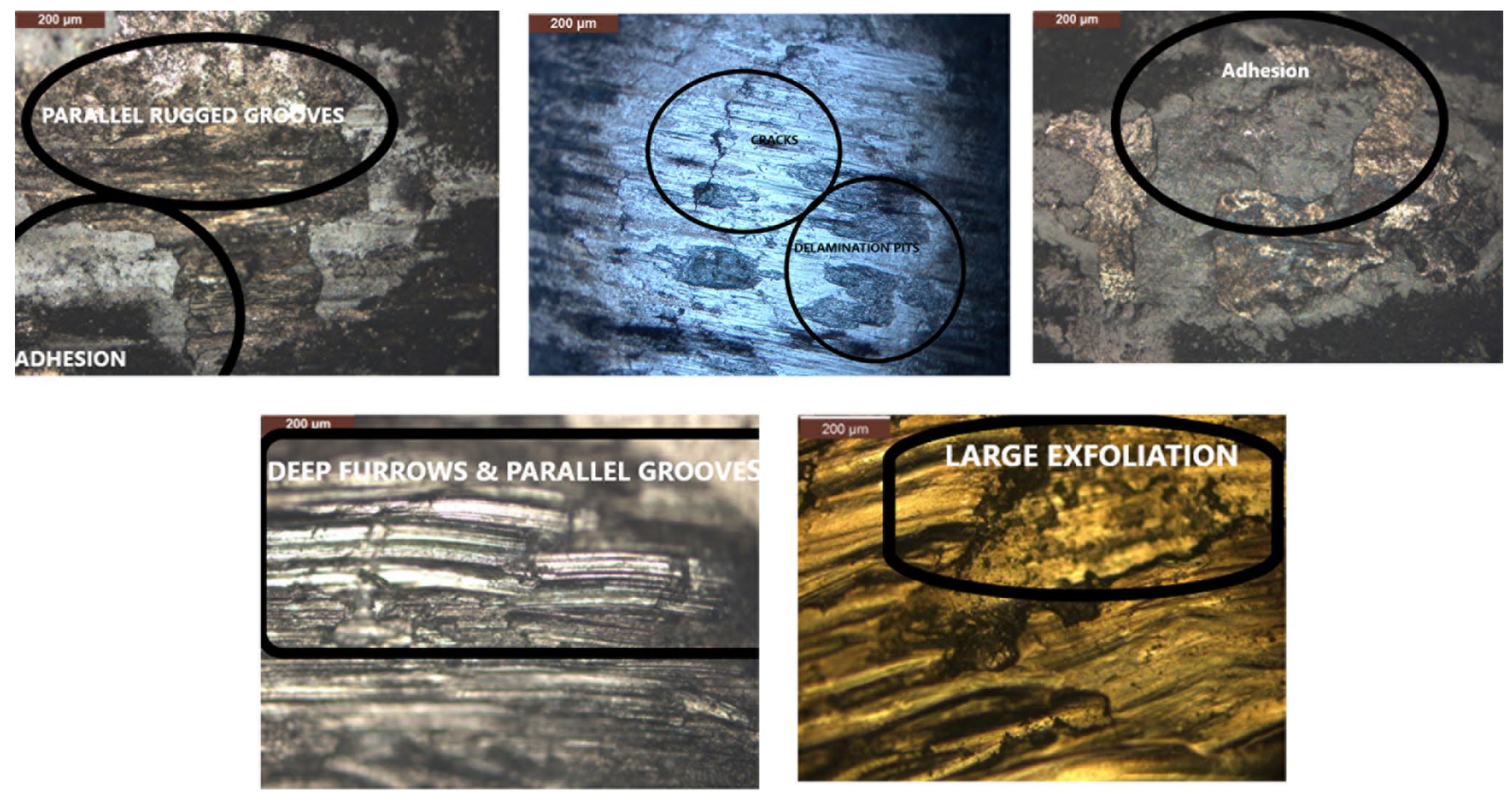

Fig. 12 Optical micrographs of wear scar on composite samples under dry sliding
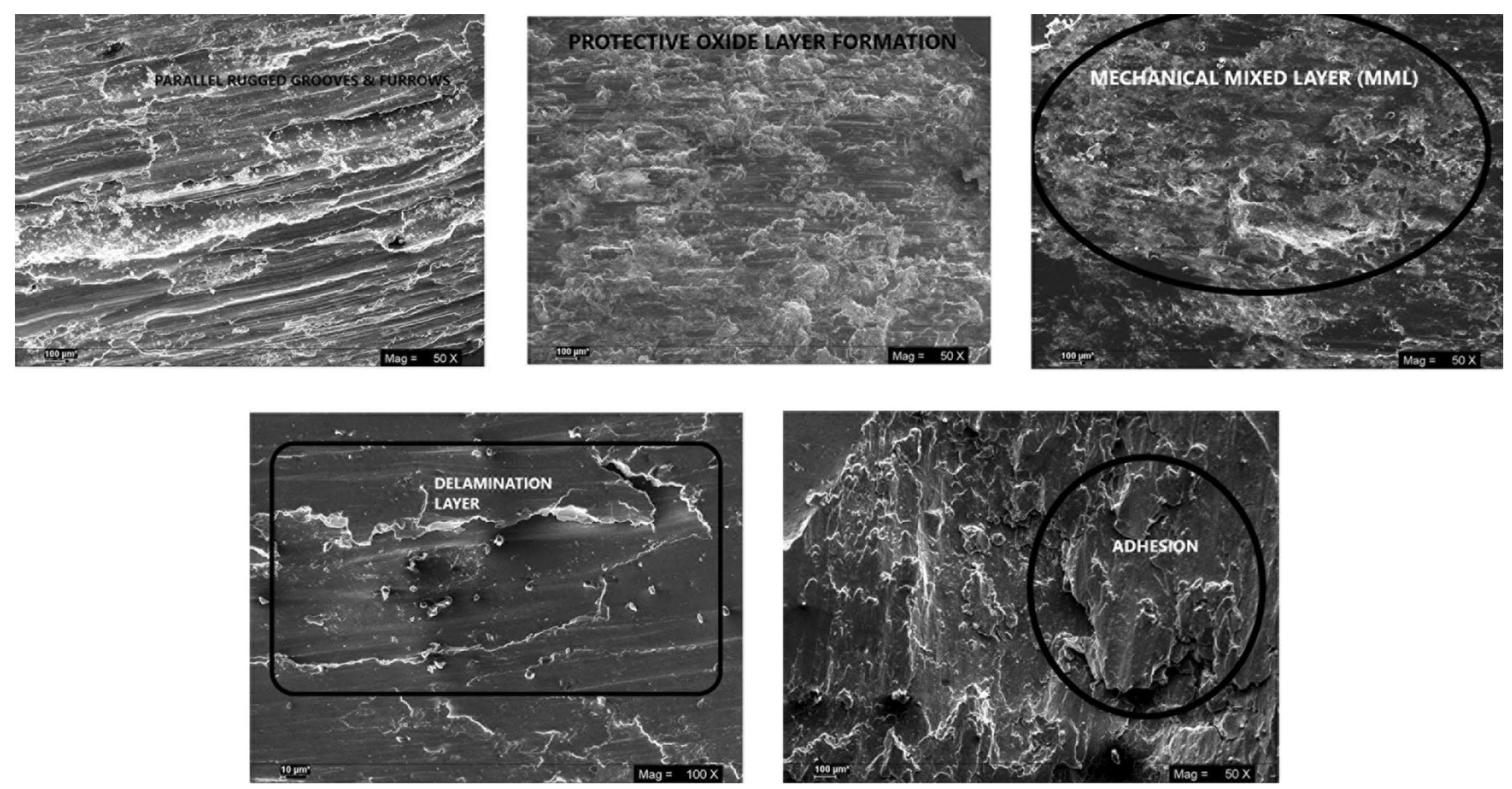

Fig. 13 SEM micrographs of wear scar on composite samples under dry sliding

\&SAE20W50 lubricating oil. The dominating wear mechanism is the delamination wear as well as oxides debris which are formed due to discontinuous oxide layer formed on the wear scar zone is shown in Fig. 17. EDS analysis conforms the formation of oxide layer on the scar zone is shown in Fig. 19a. Wear scar obtained for the lubricants 
Fig. 14 EDS micrographs of wear scar analysis on composite samples under dry sliding

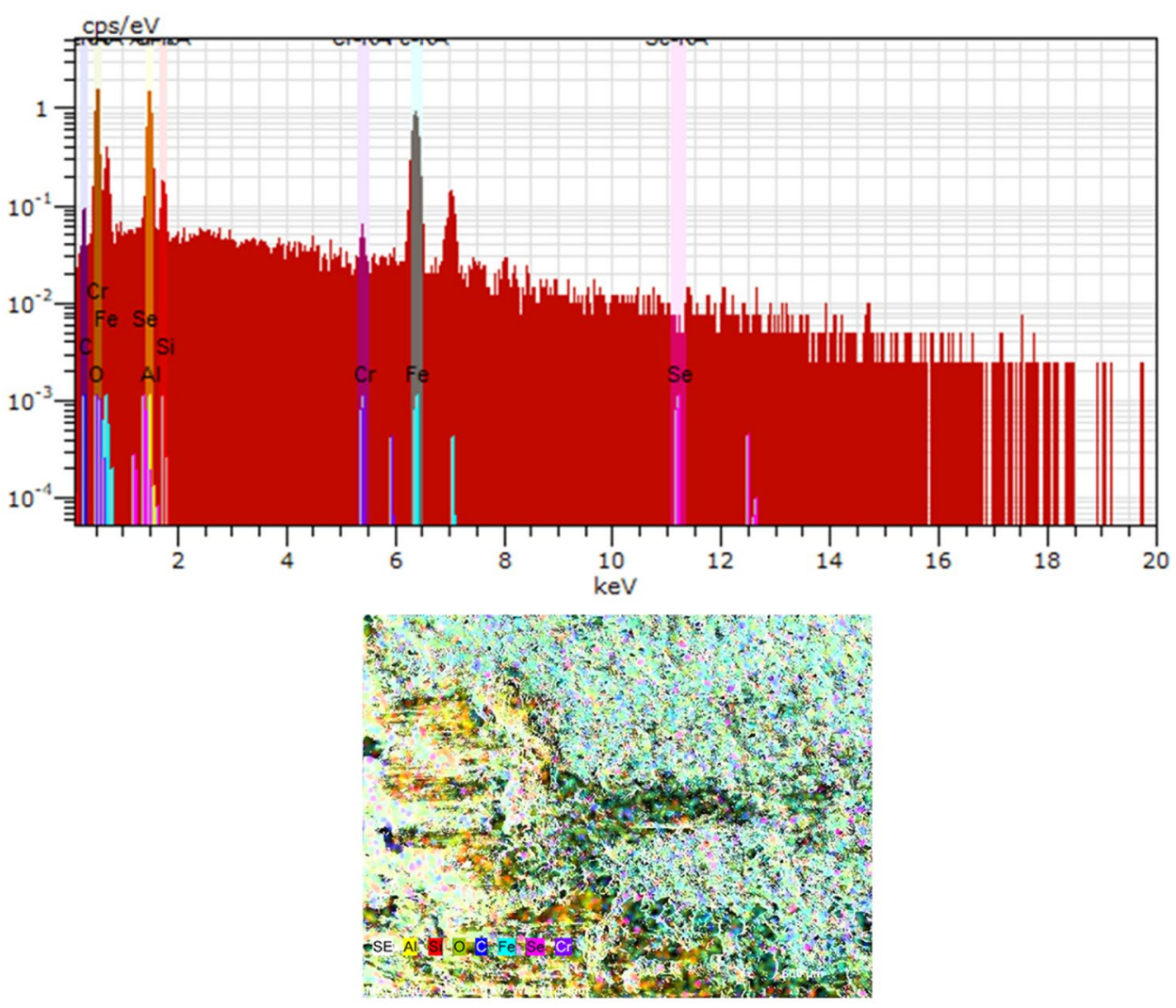

Fig. 15 3-D Surface Profilometer micrographs of wear scar on composition samples on composite samples under dry sliding

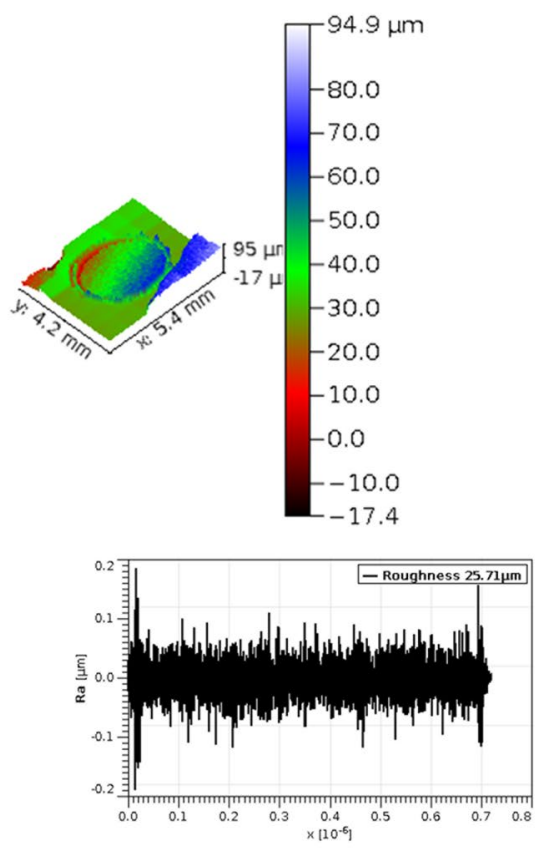

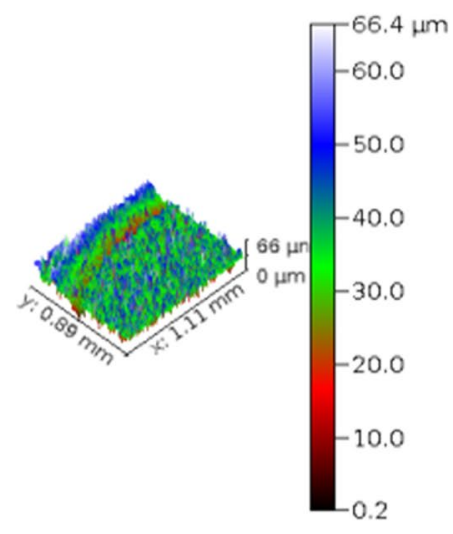

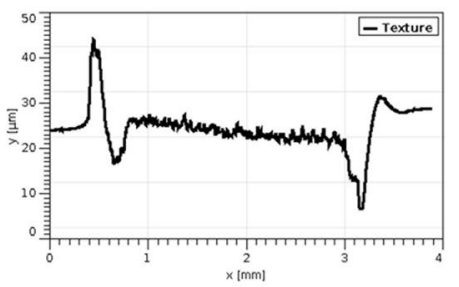

with nano additives shows smooth scar surface and continuous oxide layer protective film formation is shown in Fig. 17. The formation of the oxide layer is attributed to the tribo-physicochemical reaction of the GNP nano additive on the sliding interface. The GNP particles present in the lubricating oil reduce the direct metal-metal contact by offering mending, self-polishing and roll ball bearing mechanism on the sliding interface reduces the 
Fig. 16 Optical micrographs of wear scar on composite samples under lubricating sliding
Fig. 17 SEM micrographs of wear scar on composite samples under lubricating sliding
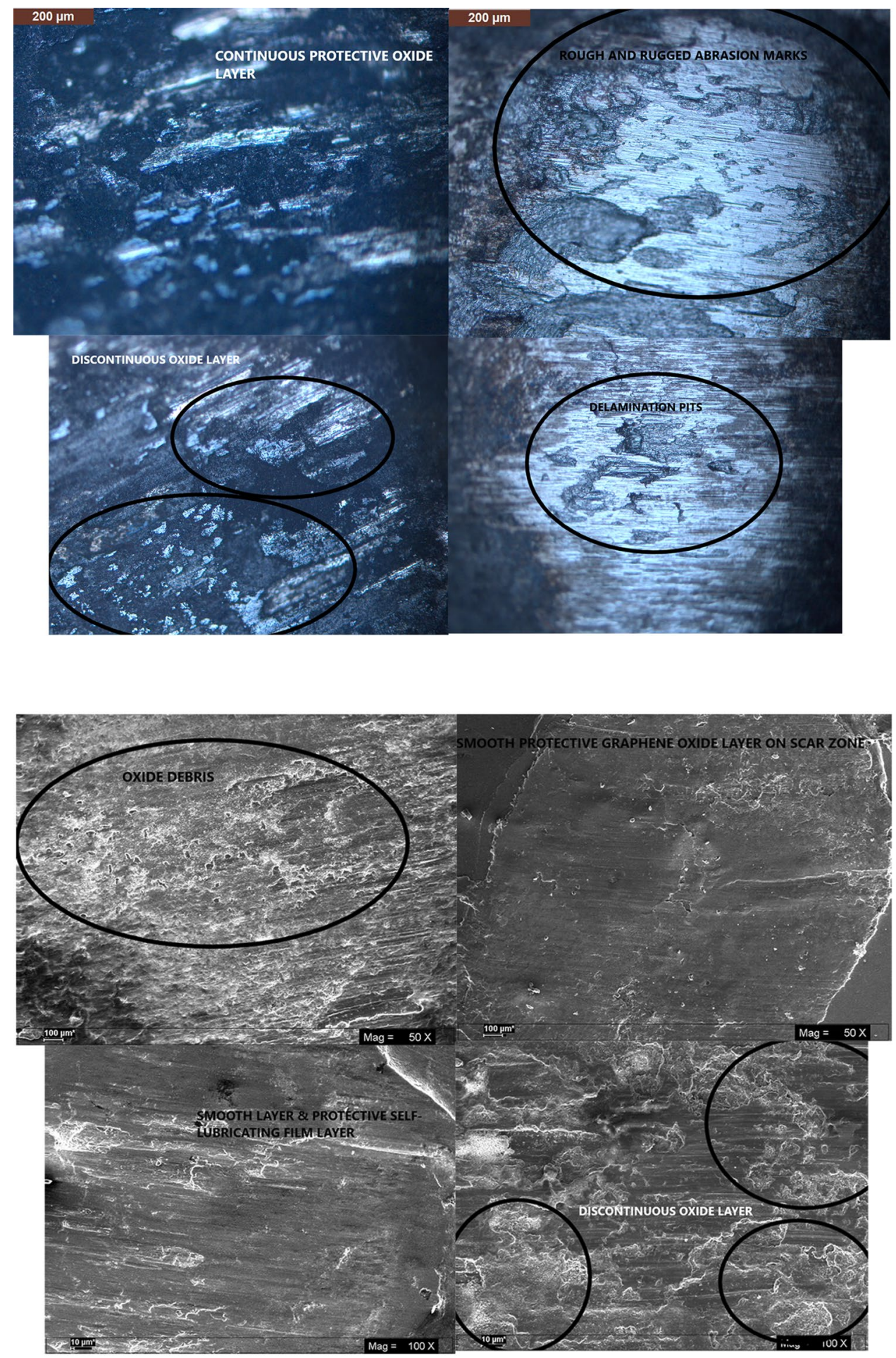

possibility of wear as shown in Fig. 18. A smooth low shear stress junction of graphene oxide layer film is formed at the interface shown in figures is responsible for the reduction in the COF and wear of the fabricated samples. This protective film is having anti-friction and anti-wear properties and provide good degree of agreement with the obtained results. It is found that an adsorbed Graphene Oxide layer is formed on the wear scar which reduces the 


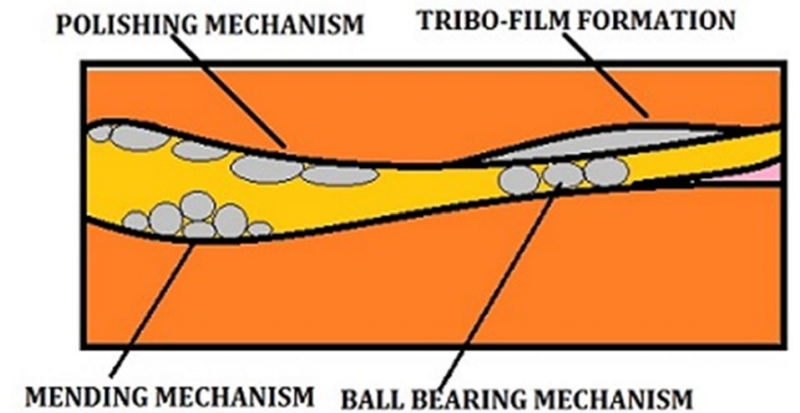

Fig. 18 Lubrication mechanisms offered by nano-additives in lubricating oil

wear of the material. EDS and Raman analysis conforms the formation of Graphene Oxide layer formation is shown in Figs. $19 \mathrm{~b}$ and 20 respectively. 3D surface roughness is also performed on the wear scar obtained with different lubricants, revels that the scar zone with GNP particles as lubricant nano-additives decreases the surface roughness and lead to obtained smooth surface of the scar zone compared to the PAO-4 and SAE20W50 lubricating oil. The surface roughness obtained with different lubricants i.e. PAO-4 base lubricant oil, SAE20W50 commercial engine oil, PAO-4 + 0.5 wt $\%$ GNP, PAO-4 + 0.5 wt $\%$ GNP + 0.5 wt $\%$
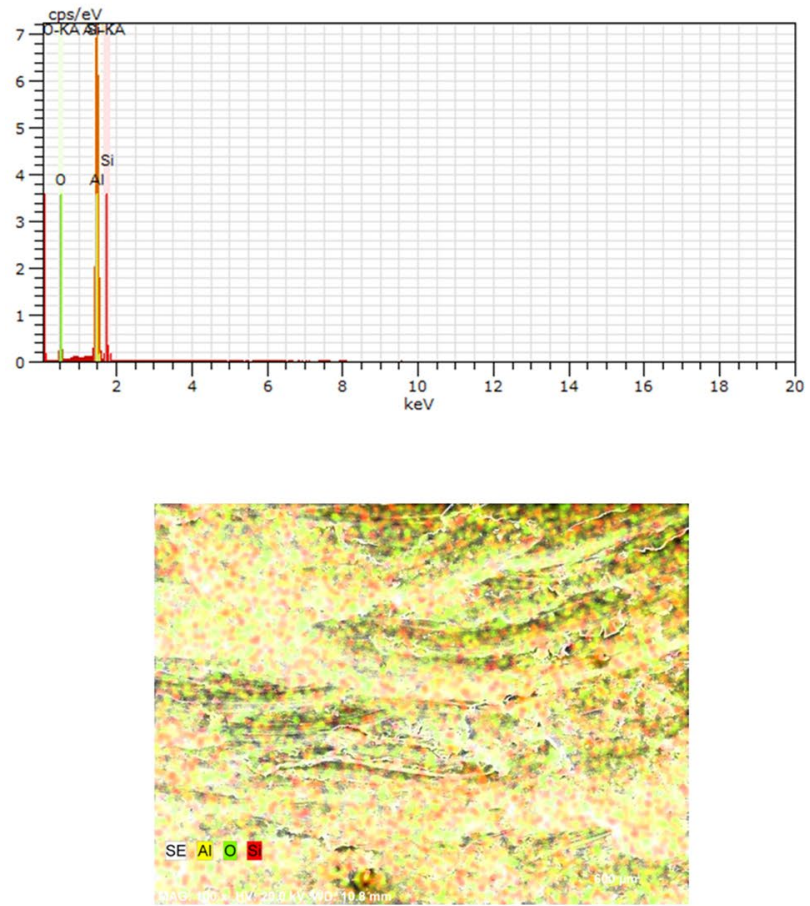

Oleic Acid (OA) on the scar zone is shown in Fig. 21a-d respectively.

\section{Conclusion}

The focus of this present study is to investigate the possible friction and wear reduction mechanism influenced by $\mathrm{n}-\mathrm{Al}_{2} \mathrm{O}_{3}$ as reinforcement in composite samples and GNP as nano-additive in lubricating oil. Following are the conclusive points:

- Under dry sliding conditions Friction Coefficient increases for advanced composite in the range 2.03$19.92 \%$ compared to the Eutectic Al-Si alloy sample. Reduction in the wear volume is reported in the range $22.43-67.75 \%$ compared to the base composition. Increase in the surface roughness due to relative sliding is decreases for the composite sample by $43.45-73.16 \%$ compared to the base composition.

- Under lubricating conditions reduction in the COF is reported to be in range from $47.35-68.18 \%$ with PAO-4 + 0.5 wt $\%$ GNP + 0.5 wt $\%$ Oleic Acid lubricant compared to SAE20W50 and PAO-4 lubricating oil. Wear volume reduction is reported to be in range from $21.58 \%-72.92 \%$ with PAO- $4+0.5$ wt $\%$ GNP + 0.5 wt $\%$
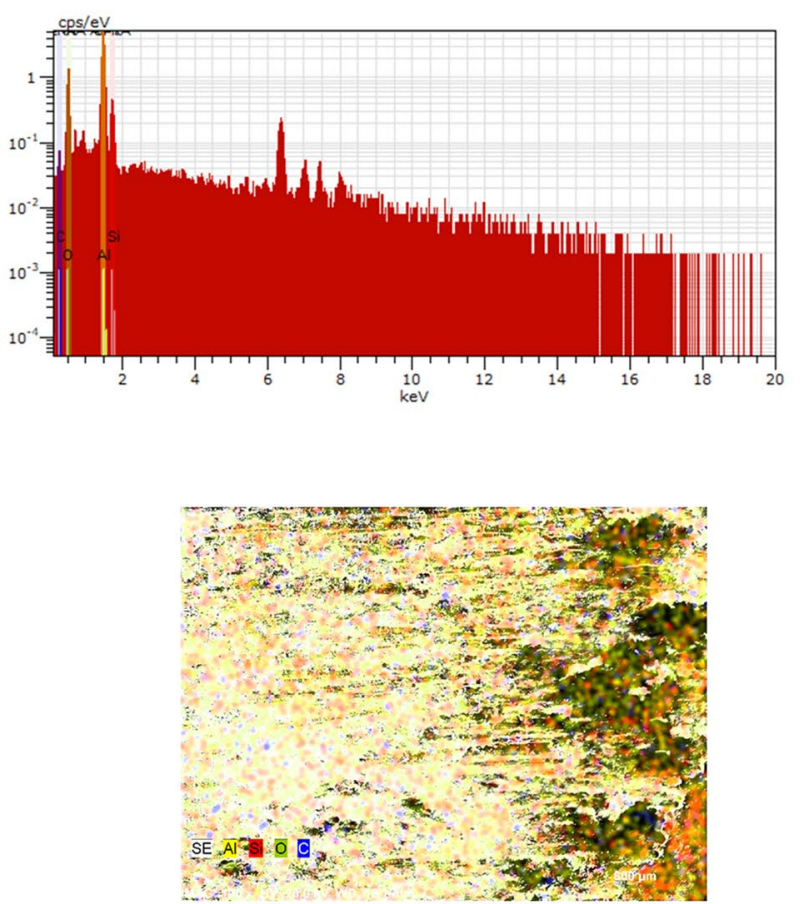

Fig. 19 a EDS micrographs of wear scar analysis on composite samples under lubricating sliding. $\mathbf{b}$ EDS micrographs of wear scar analysis on composite samples under lubricating sliding with GNP as nano-additive 


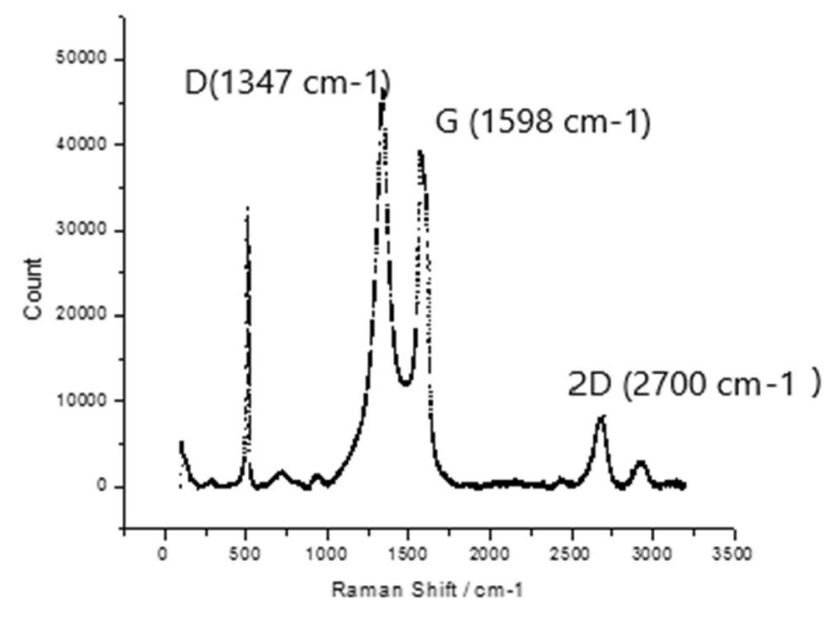

Fig. 20 Raman Analysis on the wear scar
Oleic Acid lubricant in comparison to PAO-4 and SAE20W50 lubricant. Frictional surface roughness minimized in the range of $50-68.9 \%$.

- The severe wear reduces with an increase in the reinforcement concentration as reinforcement restricts propagation of the wear cracks and it is reported that above certain reinforcement content no severe wear occurs. Tribofilm formation, protective oxide film with low shear stress junction are also reported which help to enhance lubrication mechanism of tribo-pair reduces frictional traction.

- Adhesion, Abrasion, 3-body abrasion, severe plastic and shear deformation are the dominating wear mechanism under dry sliding conditions and abrasion and plastic deformation are two prominent wear mechanism under lubricating sliding conditions.
Fig. 21 a 3-D Surface roughness of wear scar on composition samples with PAO-4 lubricating sliding conditions. b 3-D Surface roughness of wear scar on composition samples with SAE20W50lubricating sliding conditions. c 3-D Surface roughness of wear scar on composition samples with PAO-4 + 0.5 wt\% GNP lubricating sliding conditions. d 3-D Surface roughness of wear scar on composition samples with PAO- $4+0.5$ wt $\%$ GNP + 0.5 wt $\%$ Oleic Acid (OA) lubricating sliding conditions
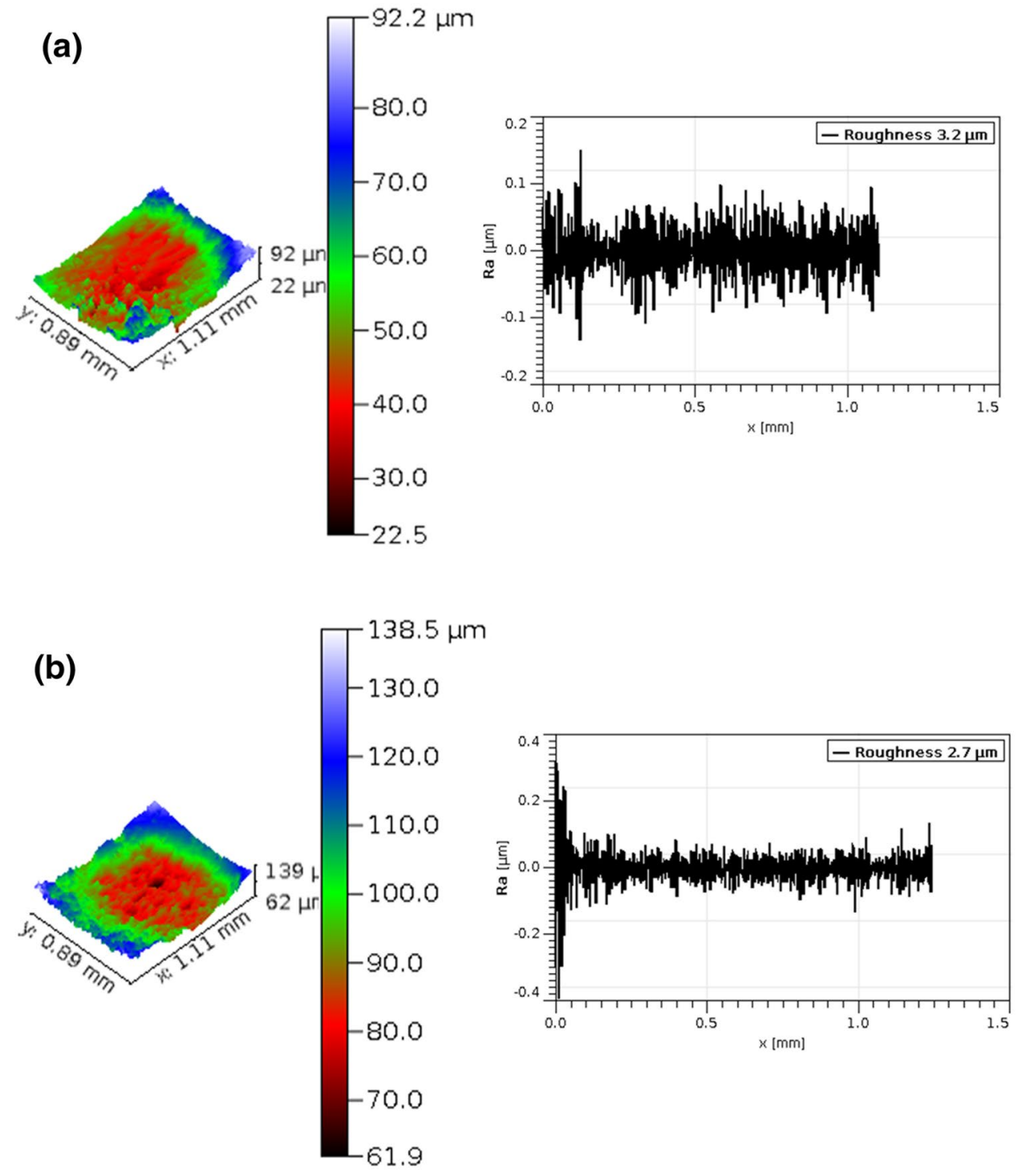

SN Applied Sciences 
Fig. 21 (continued)

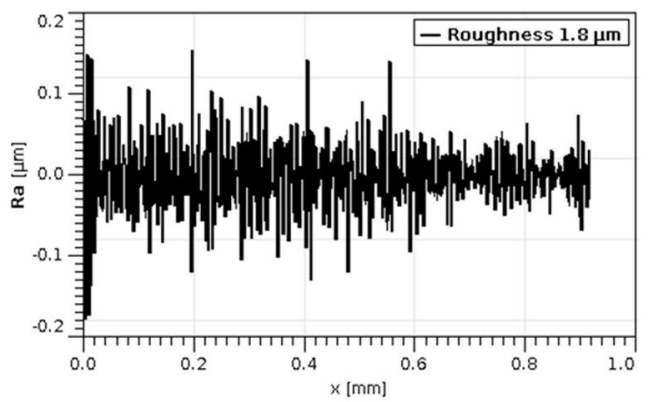

$-120.0$

115.3

$177.0 \mu \mathrm{m}$

$-170.0$

$-160.0$

150.0

$-140.0$

130.0

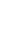

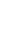

(d)

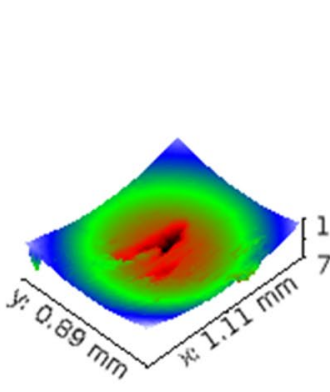

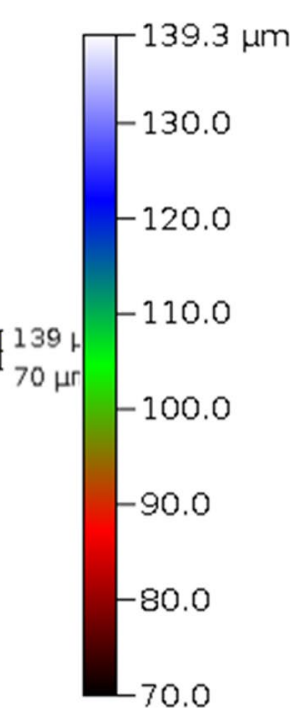

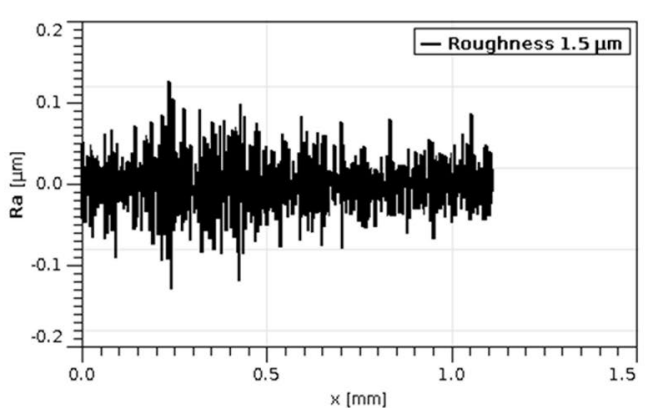

\section{Compliance with ethical standards}

Conflict of interest The authors declare that they have no conflict of interest.

\section{References}

1. Johnson KL (1995) Contact mechanics and the wear of metals. Wear 190:162-170

2. Goryacheva IG (2013) Contact mechanics in tribology. Springer, Berlin, p 61

3. Kragelsky IV (1968) Friction and wear. Mech Eng

4. Hsu SM, Richard SG (2005) Boundary lubricating films: formation and lubrication mechanism. Tribol Int 38:305-312

5. Ibrahim IA, Mohamed FA, Lavernia EJ (1991) Particulate reinforced metal matrix composites-a review. J Mater Sci 26:1137-1156
6. Allison JE, Gerald SC (1993) Metal-matrix composites in the automotive industry: opportunities and challenges. JoMm 45:19-24

7. Casati R, Maurizio V (2014) Metal matrix composites reinforced by nano-particles-a review. Metals 4:65-83

8. Srivatsan TS, Ibrahim IA, Mohamed FA, Lavernia EJ (1991) Processing techniques for particulate-reinforced metal aluminium matrix composites. J Mater Sci 26:5965-5978

9. Das $S$, Chandrasekaran M, Samanta S, Kayaroganam P, Davim P (2019) Fabrication and tribological study of AA6061 hybrid metal matrix composites reinforced with SiC/B4C nanoparticles. Ind Lubric Tribol

10. Suresh S, Harinath G, DevaKumar MLS (2019) Mechanical properties of AA7075/Al2O3/SiC nano-metal matrix composites stircasting method. J Inst Eng India: Ser D 100:43-53

11. Williams JC, Edgar A Jr (2003) Progress in structural materials for aerospace systems. Acta Mater 51:5775-5799

12. Davies G (2012) Materials for automobile bodies. ButterworthHeinemann, Oxford 
13. Srivyas PD, Charoo MS (2020) Friction and wear characterization of spark plasma sintered hybrid aluminum composite under different sliding conditions. J Tribol 1:1-29

14. Srivyas PD, Charoo MS (2020) Friction and wear reduction properties of GNP nano-particles as nano-additive for $\mathrm{Al}-\mathrm{Si}+\mathrm{Al} 2 \mathrm{O} 3$ composite/Chromium plated steel tribopair. Jurnal Tribologi 25:83-101

15. Srivyas PD, Charoo MS (2020) Nano lubrication behaviour of Graphite, h-BN and Graphene Nano Platelets for reducing friction and wear. Mater Today: Proc

16. Garbiec D, Jurczyk M, Levintant-Zayonts N, Mościcki T (2015) Properties of Al-Al2O3 composites synthesized by spark plasma sintering method. Arch Civ Mech Eng 15:933-939

17. Bhatt JN, Balachander SS, Karthikeyan R, Peshwe DR, Murty BS (2012) Synthesis of nanostructured Al-Mg-SiO2 metal matrix composites using high-energy ball milling and spark plasma sintering. J Alloys Compd 536:S35-S40

18. Zummo SA (2014) ffih

19. Al-Qutub AM, Khalil A, Saheb N, Hakeem AS (2013) Wear and friction behavior of Al6061 alloy reinforced with carbon nanotubes. Wear 297:752-761

20. Gürler R (1999) Sliding wear behavior of a silicon carbide particle-reinforced aluminum-magnesium alloy. J Mater Sci Lett 18:553-554

21. Lim SC, Gupta M, Ren L, Kwok JKM (1999) The tribological properties of $\mathrm{Al}-\mathrm{Cu} / \mathrm{SiCp}$ metal-matrix composites fabricated using the rheocasting technique. J Mater Process Technol 89:591-596

22. Alaneme KK, Akintunde IB, Olubambi PA, Adewale TM (2013) Fabrication characteristics and mechanical behaviour of rice husk ash-Alumina reinforced Al-Mg-Si alloy matrix hybrid composites. J Mater Res Technol 2:60-67

23. Alaneme KK, Olubambi PA, Afolabi AS, Bodurin MO (2014) Corrosion and tribological studies of bamboo leaf ash and alumina reinforced Al-Mg-Si alloy matrix hybrid composites in chloride medium. Int J Electrochem Sci 9:5663-5674

24. Wan Q, Jin Y, Sun P, Ding Y (2014) Rheological and tribological behaviour of lubricating oils containing platelet MoS 2 nanoparticles. J Nanopart Res 16:2386

25. Charoo MS, Wani MF (2017) Tribological properties of h-BN nanoparticles as lubricant additive on cylinder liner and piston ring. Lubr Sci 29:241-254

26. Charoo MS, Wani MF (2016) Tribological properties of IF-MoS 2 nanoparticles as lubricant additive on cylinder liner and piston ring tribo-pair. Tribol Ind 38:156-162

27. Kandanur SS, Rafiee MA, Yavari F, Schrameyer M, Yu ZZ, Blanchet TA, Koratkar N (2012) Suppression of wear in graphene polymer composites. Carbon 50:3178-3183

28. Liao Y, Pourzal R, Wimmer MA, Jacobs JJ, Fischer A, Marks LD (2011) Graphitic tribological layers in metal-on-metal hip replacements. Science 334:1687-1690

29. Das S, Mondal DP, Sawla S, Ramakrishnan N (2008) Synergic effect of reinforcement and heat treatment on the two body abrasive wear of an $\mathrm{Al}-\mathrm{Si}$ alloy under varying loads and abrasive sizes. Wear 264:47-59

30. Chawla N, Chawla KK (2006) Microstructure-based modeling of the deformation behavior of particle reinforced metal matrix composites. J Mater Sci 41:913-925

31. Kok M (2005) Production and mechanical properties of Al2O3 particle-reinforced 2024 aluminium alloy composites. J Mater Process Technol 161:381-387

Publisher's Note Springer Nature remains neutral with regard to jurisdictional claims in published maps and institutional affiliations. 